\title{
DEVELOPMENT OF A PROPOSAL FOR A PROGRAM OF \\ POST-REHABILITATION CONDITIONING IN A PRIVATELY-OWNED \\ COMMERCIAL SETTING
}

\author{
A Project Report \\ Presented to the Faculty of \\ California Polytechnic State University, \\ San Luis Obispo \\ In Partial Fulfillment \\ Of the Requirements for the Degree \\ Master of Science in Kinesiology
}

Starlene A. Marshall

May 2010 
(C) 2010

Starlene A. Marshall

ALL RIGHTS RESERVED 


\section{COMMITTEE MEMBERSHIP}

TITLE: Development of a Proposal for a Program of PostRehabilitation Conditioning in a Privately-Owned Commercial Setting

AUTHOR: $\quad$ Starlene A. Marshall

DATE SUBMITTED: May, 2010

COMMITTEE CHAIR: $\quad$ Steven C. Davis, Ph.D., R.C.E.P.

COMMITTEE MEMBER: Suzanne Phelan, Ph.D.

COMMITTEE MEMBER: Jennifer Olmstead, M.S., C.S.C.S. 


\begin{abstract}
Development of a Proposal for a Program of Post-Rehabilitation Conditioning in a Privately-Owned Commercial Setting

Starlene Marshall

May, 2010
\end{abstract}

Chronic disease is a serious health problem that can be debilitating or even life threatening. Inactivity has been identified as a major contributor to the burden of disease. More than 50\% of American adults are not regularly physically active. Moreover, physical activity is beneficial in the treatment of persons with chronic disease and disability (ACSM's Guidelines, 2010; NCCDPHP, 2004). PostRehabilitation Programs are a growing concept in the medical community and fitness industry. Post-rehab conditioning programs encompass: certification, collaboration with the medical community, and a systematic protocol. Fitness assessments, exercise programming and documentation to the medical authority comprise an important part of post-rehab programs.

The purpose of this project was to evaluate the current necessity and variability of post-rehab programs and to develop a post-rehabilitation conditioning program for Kennedy Club Fitness. A needs assessment was conducted through a review of relevant literature and interviews with medical professionals in the community pertaining to commonly-treated medical conditions and referral to local health clubs. A plan for a post-rehabilitation conditioning program was developed in conjunction with three fitness guidelines based on the survey results. The plan consisted of a proposed protocol for the post-rehab program, certification through the 
American Academy of Health, Fitness and Rehabilitation Professionals for trainers of Kennedy Club Fitness, forms and materials to be used in the program and health clinics to be offered to club members. The Post-rehab Conditioning Program would comprise a trial membership to the club by referral from a medical professional, an initial consultation, conditioning appointments to establish the exercise plan and progress reports to the referring medical professional. 
List of Tables ............................................................ ix

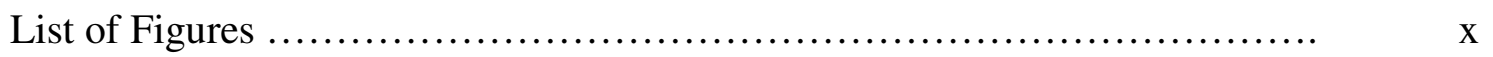

\section{Chapter}

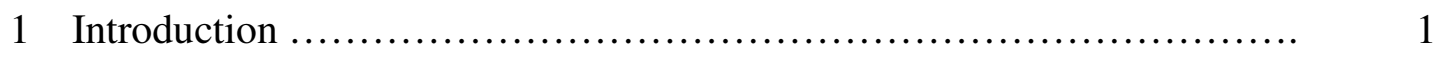

Background of the Study ...................................

Statement of the Problem .................................... 4

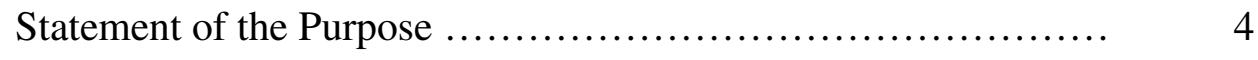

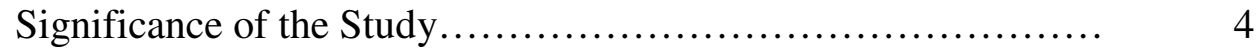

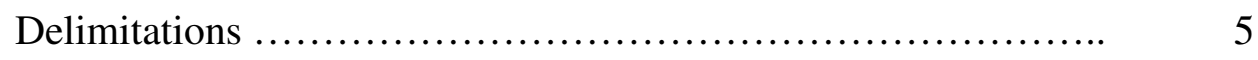

Assumptions............................................... 5

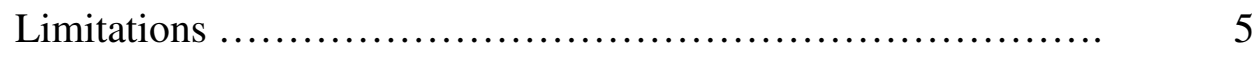

Research Questions......................................... 6

Definition of Terms ....................................... 6

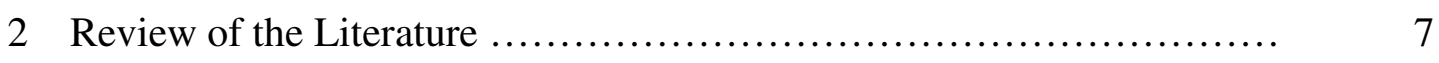

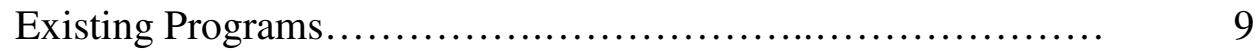

Certifying Agencies....................................... 11

Medical Conditions......................................... 14

Cardiovascular Disease................................... 15

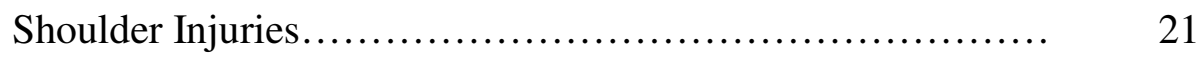

Musculoskeletal Conditions................................ $\quad 23$ 
Back Injuries..................................... 23

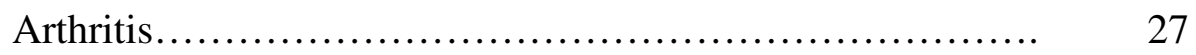

Joint Replacements................................... 29

Fitness programming.................................... 33

Demographics........................................ 35

3 Methods and Procedures ...................................... 37

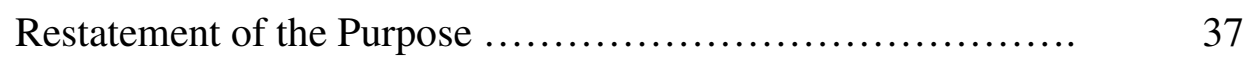

Design............................................. 37

Subjects............................................. 37

Procedures ............................................ 37

Needs Assessment.................................. 37

Pilot Testing Informal Interviews..................... 38

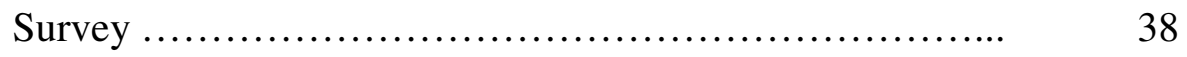

Data Analysis ..................................... 39

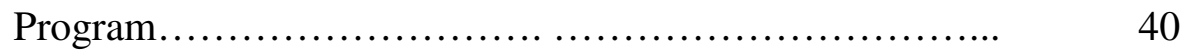

4 Results and Discussion ....................................... 42

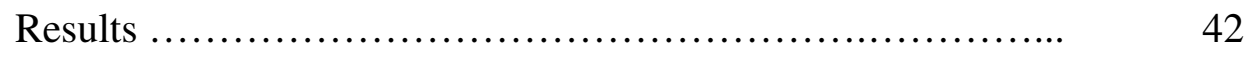

Pilot-test Interviews.............................. 42

Demographics of Club Members...................... 43

Survey Results................................... 43

Program........................................... 44

Discussion .......................................... 49 
5 Summary, Conclusions and Recommendations ..................... 53

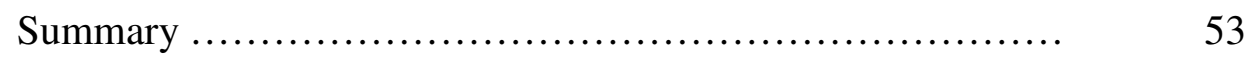

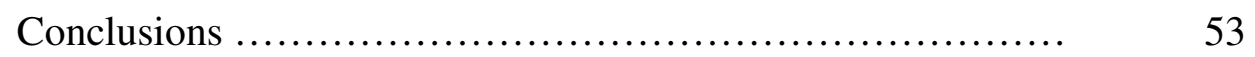

Recommendations ................................... 54

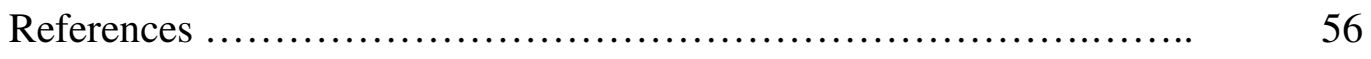

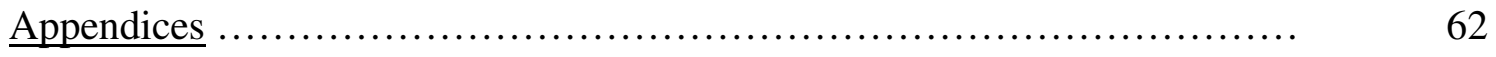

A. Survey Phone List............................................ 62

B. Informed Consent/Survey Script............................. 65

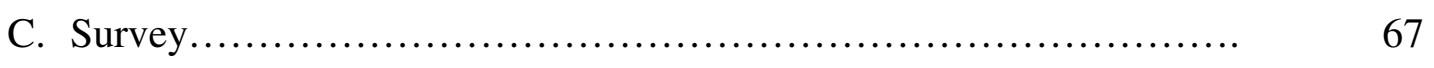

D. Program Outline.............................................. 69

E. Program Description, Referral Sheet and Progress

Report................................................ 77

F. Consultation Forms ......................................... 81

Client Data Questionnaire.............................. $\quad 82$

PAR-Q Medical Status................................. 83

Healthy Living Lifestyle Assessment Questionnaire........... 84

Musculoskeletal Screening............................. 87

G. Lecture/Clinic Information................................ 89

H. Brochure................................................ 94 


\section{List of Tables}

$\underline{\text { Table }}$

1. Survey Results..............................................
Page

44 
List of Figures

Figure $\quad$ Page

1. Flow Chart................................................... 45 


\section{Chapter 1}

Introduction

\section{Background of the Study}

Chronic disease is a serious health problem that can be debilitating or even life threatening. Inactivity has been identified as a major contributor to the burden of disease. According to the United States Department of Health and Human Service's Centers for Disease Control and Prevention (CDC), more than 1.7 million people die of a chronic disease each year. The CDC also state, "Much of the chronic disease burden is preventable. Physical inactivity and unhealthy eating contribute to obesity, cancer, cardiovascular disease, and diabetes. Together, these two behaviors are responsible for at least 400,000 deaths each year"(NCCDPHP, 2004; USCDC, 2006). Although regular physical activity is recommended for disease prevention and health promotion, many people are not physically active.

The effect of chronic conditions has increased the demand for many health professionals; including fitness professionals such as personal trainers. It is a trainer's duty to encourage and motivate a person to stay active, as well as guide the individual through an exercise routine. "Exercise prescriptions are designed to enhance physical fitness, promote health by reducing risk factors for chronic disease (e.g. high blood pressure, glucose intolerance), and ensure safety during exercise participation" (ACSM Guidelines, 2000, p. 139). Reasons for opting to hire a personal trainer vary depending on the individual. In the past, individuals have used a personal trainer's service on their own accord for motivation or more rapid results. More recently, individuals are utilizing a personal trainer's services because it has been suggested by 
their physicians. Doctors simply do not have the time, or in some cases the in-depth knowledge of exercise programming, that a personal trainer can offer. Medical doctors do not usually specialize in exercise physiology. Therefore, fitness trainers can help this patient population more so than previously thought (Schnirring, 2000). The expanding knowledge of exercise and the health benefits that follow have increased the justification for utilizing a personal trainer. An advantage may be as an alternative to traditional medical care. Using a health club and its resources may be a cost-effective means of treatment compared to medications and medical bills. Many of the health problems Americans face can be decreased in severity with regular physical activity. The benefits of an active lifestyle are well documented (Warburton, Nicol, \& Bredin, 2006). However, a majority of Americans do not meet the recommendations (NCCDPHP, 2004; USCDC, 2006). The direct medical cost associated with physical inactivity was $\$ 29$ billion in 1987 and nearly $\$ 76.6$ billion in 2000 (www.cdc.gov retrieved, 11/19/2004). That number has since escalated to the trillions. The medical care costs of people with chronic diseases account for more than $75 \%$ of the nation's $\$ 2$ trillion medical care costs (USCDC, 2006).

Many people are prone to encounter the previously mentioned ailments; and some adults have one or more major health problems continuing in a cycle of medical care and expenses. "Managed care has created a need for patients/clients to seek alternative care for the management of their injuries/disease. Cutbacks in reimbursement of services to traditional medical providers (e.g., physicians, physical therapists, and chiropractors) have provided an opportunity to develop medically supervised fitness programs or post-rehabilitation" 
(www.afpafitness.com/articles/PostRehab,11/22/04). Barriers to physical activity promotion by medical providers have been identified as lack of time, insufficient knowledge, belief that activity promotion is ineffective, lack of reimbursement and resources (Page, 2005; Smitherman, Kendzor, Grothe, \& Dubbert, 2007).

Post-Rehabilitation Programs are a growing concept in the medical community and fitness industry. Individuals who have exhausted other resources and have received maximum benefit from physical therapy may be referred by their physicians or other medical professionals to a local health club offering a Post-Rehab Conditioning program. Some of the common chronic ailments that require thorough medical care and that would benefit from exercise include, but are not limited to, cardiovascular disease and stroke; arthritis such as rheumatoid and osteoarthritis; shoulder injuries, and the very common "back pain", such as a cervical or lumbar strain. Total hip and knee replacements are also other common medical conditions which are often caused by one of the above mentioned existing conditions (Bean, Vora, \& Frontera, 2004; Murrell \& Walton, 2001; Suomi \& Collier, 2003; Thompson, et al. 2003; www.cdc.gov/nccdphp/dnpa, 2006, 2009). In summary, supervised exercise programs referred by medical professionals are essential in promoting optimum health and/or recovery. Hence the health club industry should be readily prepared. Patients are making fewer doctor visits and fewer physical therapy visits, but they still need guidance (Schnirring, 2000). Therefore, personal trainers should acquire advanced certification(s) and expand their businesses to assist the unfit population or any person with a health risk or medical condition. 


\section{$\underline{\text { Statement of the Problem }}$}

Physical inactivity is a major health problem in the United States. More than $50 \%$ of American adults are not regularly physically active. Moreover, physical activity is beneficial in the treatment of persons with chronic disease and disability (ACSM's Guidelines, 2010; NCCDPHP, 2004). Patients have less insurance coverage for doctor and physical therapy visits, but they still need guidance and/or supervision. Kennedy Club Fitness lacked a plan/option to better assist people with special considerations; those with medical conditions/injuries, for which the researcher and employee perceived a need.

\section{$\underline{\text { Statement of the Purpose }}$}

The purpose of the project was to evaluate the current necessity and variability of post-rehab programs and to develop a Post-Rehabilitation Conditioning Program for Kennedy Club Fitness in Arroyo Grande, California. The program design provided guidance to fitness instructors and expansion of personal training in Kennedy Club Fitness. The services to be offered had the potential to increase clientele, thus increasing revenue, along with establishing a community medical network. This program was not intended to diagnose, cure, or by-pass other medical professionals such as physical therapists or chiropractors. It was yet another step in the care continuum to further the improvements made by the aforementioned professionals.

\section{$\underline{\text { Significance of the Study }}$}

The Post-Rehab program may enhance the overall well-being of the club members. As a local health club, it will have more to offer the community and 
encourage healthful lifestyles for all populations. This program may expand in future years to better assist the population and meet the growing need for supervised exercise programs.

\section{$\underline{\text { Delimitations }}$}

This project was delimited to:

- A Needs Assessment based on literature review conducted between December, 2004, and March, 2006.

- Telephone surveys to local medical professionals in San Luis Obispo County: January, 2006, through February, 2006.

- Development of a Post-rehab Conditioning Program for Kennedy Club Fitness, 1299 James Way, Arroyo Grande, CA., December, 2004, through May, 2006.

\section{$\underline{\text { Assumptions }}$}

- It was an assumption that medical professionals provided complete and honest answers.

- It was an assumption that the responses to the surveys were representative of a range of disabilities/medical conditions present in the county.

- It was assumed there was a concern on part of the health professional about the continued rehabilitation of their patients.

\section{$\underline{\text { Limitations }}$}

This study was limited by the following factors:

- The response size of medical professionals surveyed. 
- There was limited support from higher management at Kennedy Club Fitness for further development of the project.

\section{$\underline{\text { Research Questions }}$}

1. What was the current necessity for post-rehab programs?

2. What was the variability of post-rehab programs?

\section{$\underline{\text { Definition of Terms }}$}

Chronic disease A non-acute medical condition or syndrome, for instance lifestyle-related disorders such as cardiovascular disease and musculoskeletal conditions.

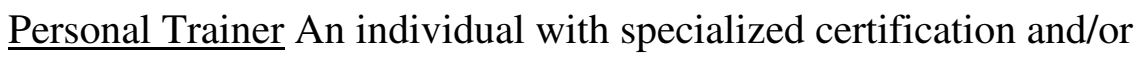
qualification in health and fitness, specifically exercise training with the occupation of exercise programming and supervision of a person's exercise routine.

$\underline{\text { Post-Rehabilitation (post-rehab) }}$ The development and implementation of fitness programming for clients with special population and post-rehab conditions (AAHFRP, 2001). Post-rehab does not purport to provide any aspect of medical treatment of a client's condition. The post-rehab program should include: Fitness Assessments, Strength Training, Flexibility Training, Cardiovascular Training, and Functional Conditioning (p. 1, section 2). 


\section{Chapter 2}

\section{Review of the Literature}

The purpose of the project was to evaluate the current necessity and variability of post-rehab programs and to develop a Post-Rehabilitation Conditioning Program for Kennedy Club Fitness, Arroyo Grande, California.

The literature search was conducted using Medscape, Medline, PubMed, and Expanded Academic Index. Government websites, accredited organizations and research articles were viewed along with other sources such as websites, online publications and review articles. This review of the literature includes topics pertaining to exercise and rehabilitation for various medical conditions and the necessary procedures to follow when supervising a post-rehab client. First, existing Post-Rehab programs are identified. It is important to recognize other facilities/companies offering Post-Rehab and to compare those programs. Secondly, various certifying agencies are identified and the certifications and/or education required. This information is valuable not only to the person inquiring about certification but also to the prescribing medical professional. Next, specific medical conditions are addressed to help identify the most common conditions referred by medical professionals, as well as fitness programming which helps identify the appropriate protocol when working with a post-rehab client. Local demographics will also be identified. This information is important to become familiar with the clientele base. Lastly, interviews from specialists will be addressed. This is necessary to gain a professional perspective and justify the included topics. 
An article, "Referring Patients to Personal Trainers: Benefits and Pitfalls", The Physician and Sportsmedicine: News Briefs, 28, (1) Retrieved 9/15/04, stated that specific national organizations that certify personal trainers anticipate a growing need for trainers' services due to the increase of the aging population with chronic conditions. Because disability and disease increase with age, health promotion and prevention of disease are of concern. Health promotion organizations have created campaigns to encourage physical activity but, somehow there is a gap in the system of delivering and applying the information. Primary care providers have an important role in the ability to increase exercise recommendations to the public, but that may not occur. A study about physician and geriatric patient discussions (Ory et al., 2006) revealed nutrition was discussed in $48.2 \%$, physical activity in $39.2 \%$, and both physical activity and nutrition in only $22 \%$ of the encounters. The National Health Statistics Reports (NHSR) indicated 21.8 minutes as the mean time spent with a physician. And face to face contact between the physician and patient had a duration of 10 minutes or less in $16.7 \%$ of visits (Cherry et al., 2008). With time constraints and lack of reimbursement (Page, 2005; Smitherman et al., 2007) the medical community has the opportunity to recruit fitness professionals. However, the collaboration between physicians and personal trainers may have a downside. Some physicians are hesitant to refer patients to trainers based on the traditional view of personal trainers as "gym rats" or jocks, and may be concerned about trainer diagnoses or changes in the physician's original plan without consultation. Nonetheless, many companies view the physician/trainer relationship as beneficial. 
This relationship helps close the gap between medical care and fitness, allowing for a new referral and networking source.

\section{Existing Programs}

According to Branzel (2001-2002) in the last 25 years the health and fitness industry has experienced a massive amount of changes, but nothing as profound as the "hospital-based fitness center" concept. Branzel later stated, "By integrating member-based community fitness centers with clinical rehabilitation services, there is the continuum of care that flows from inpatient, outpatient, and post-rehabilitation to fitness and wellness." (www.systoc.com/Tracker/Winter01/PostRehab.asp). The majority of programs are in the realm of hospital-based centers.

Japsen (1996) reported, "Through multimillion-dollar investments, hospitals are meeting this challenge by building their own health clubs, integrating standard exercise and aerobic exercise equipment found at places like Bally and Gold's Gym with rehabilitation, wellness services and medical office facilities."

Berry (2003) was in agreement, stating, "Prevention instead of fear is the primary reason today that hospitals are creating high-tech and high-touch facilities to reach out and prevent disease from limiting the quality of life of the people in their communities" (www.rehabpub.com).

Based on an internet search, a few existing examples of post-rehabilitation programs/companies include the Health and Fitness Institute (HFI), TriHealth Fitness and Health Pavilion, REX Wellness Centers, and also information about hospitals opening their own facilities. The Health and Fitness Institute (HFI), located in Stamford Connecticutt, is a physician-approved fitness facility for special 
populations. The center integrates fitness and medicine by means of exercise programs, seminars, rehabilitative medicine, holistic care and outpatient services. The center is unique in that the average age of membership is 65 , and a health risk factor along with physician's referral is necessary to join. After joining the center the member receives an assessment from a fitness specialist, along with a specialized exercise program and documentation sent to their physician. The HFI also offers specialty classes to the community (www.rehabpub.com, 1/3/2005).

A similar facility is the TriHealth Fitness and Health Pavilion. The 110,000 square-foot fitness and wellness center located in Cincinnati, Ohio, opened in January, 1997. TriHealth Fitness and Health Pavilion provides both rehabilitation and prevention along with health and fitness programs in one building. Targeting the "medically-unfit at-risk population", the center offers a transitional phase post-rehab program; a three-month membership with the completion of therapy within 60 days and medical status obtained from a medical professional. This facility, like the previously mentioned HFI, also offers an initial assessment along with the implementation of a fitness program. "A goal of the post-rehabilitation program is to assist the unfit-at-risk member to feel comfortable integrating with a healthy member"(Branzel, 2001-2002).

The REX Wellness Centers form yet another organization combining specialized fitness programs with rehabilitation and wellness. Based on the web site, REX Healthcare offers numerous health services in multiple centers. REX Wellness of Raleigh, North Carolina, is "Wake County's first comprehensive, medicallysupervised health and wellness center"; another location is REX Wellness of Cary, 
North Carolina, offering outpatient rehabilitation and urgent care; and the most recent location is REX Wellness of Garner, North Carolina, which opened in October, 2003. All centers offer health education and access to various rehabilitation programs, such as PEAK Personalized Exercise and Joint Conditioning Program (REX Healthcare, retrieved 5/24/04).

As stated by Japsen (1996), in Modern Healthcare, "Although a few hospital fitness centers have been around for more than a decade, the Association of Hospital Health and Fitness said the number of hospital fitness centers has doubled to about 350 today from 175 in 1990."(p.1). The idea of hospital fitness centers can be further carried out to encourage existing health clubs to acknowledge and implement a similar concept. Medical fitness and wellness centers are on the rise. The Medical Fitness Association (MFA) reported a projection of 1,150 centers by 2010 . Regardless of the setting, the idea and goal is the same; to allow for a smooth transition from rehab to fitness. Local health clubs can combine fitness expertise from qualified professionals with rehabilitation services by means of incorporating local medical professionals into the already existing clubs.

Certifying Agencies

Specific certifying agencies offer what is called Post-Rehab certification for personal trainers to obtain and use in conjunction with each client's medical authority. Numerous personal training certifications are available, however, only a few organizations are taking on the role of post-rehab training for special populations. The American Academy of Health, Fitness \& Rehabilitation Professionals (AAHFRP), American Council on Exercise (ACE), and American Fitness 
Professionals \& Associates (AFPA), are a few organizations offering Post-Rehab certification. These certifications are for the already established, qualified professional to increase his/her knowledge base and accommodate the at-risk population.

The Post-Rehab Conditioning Specialist (PRCS) \& Medical Exercise Specialist (MES) are certifications available through AAHFRP. The Post Rehab Conditioning Specialist is the first or primary certification; the Medical Exercise Specialist (MES) is the next step in advanced post-rehab certification. You must meet one or more of the four prerequisites to enroll, which include: Personal Trainer certification by a nationally recognized organization, a degree in a health- or fitnessrelated discipline (i.e. physical education, nursing, recreation or exercise physiology), two years experience working in a rehab setting under a licensed medical professional, or currently licensed as a physical therapist, chiropractor, massage therapist, athletic trainer/therapist, nurse, physician, occupational therapist or physician assistant; and a current, valid CPR card is mandatory. Both certifications cover topics such as the role of the fitness professional, marketing and insurance procedures, fitness programming guidelines, and a musculoskeletal screening guide. The mission of AAHFRP is "To bridge the gap between health care and fitness by providing a forum to educate fitness professionals to work cooperatively with the medical community in developing safe and effective fitness programs for special populations and post-rehab clients" (Michael K. Jones Ph.D., www.medicalexercisespecialist.com/about.htm, 9/28/2004). 
ACE offers the advanced personal trainer certification, "Clinical Exercise Specialist". This certification allows certified trainers to work with special populations in areas of strengthening, physical conditioning, proprioceptive training, improving range of motion, neuromuscular re-education, balancing extremity strength, increasing muscular endurance and increasing cardiovascular function. Certain eligibility requirements must be met to receive the certification exam: 18 years of age, and 300 hours of documented work experience in program design for apparently healthy individuals and/or high-risk individuals (www.acefitness.org, retrieved 2/7/2005).

AFPA offers the Post Rehabilitative Exercise Specialist certification. "The course will teach you how to develop safe and effective post rehab fitness programs for clients with various limitations that are recovering from a variety of injuries, disease and/or treatment" (AFPA Post Rehab, retrieved 9/15/2004). The company's web site listed the suggested prerequisites along with certification topics and approximate completion time. Prerequisites include: 18 years of age, high school diploma or equivalent, documentation of 400 hours of hands-on training from a supervisor on letterhead, a Personal Trainer's certificate or equivalent from a nationally-recognized organization, and basic understanding of anatomy and resistance/cardiovascular training. Topics covered in the certification include:

"Background \& Definition of Post Rehab and Various Injuries", "Managed Care and Post Rehabilitation Conditioning”, "Liability Concerns in Rehabilitation Conditioning", "Post Rehabilitation Conditioning at the Shoulder, the Low Back, the 
Knee, the Lower Leg, Feet \& Ankle, and for Special Populations". A passing score of $90 \%$ or better is required to receive certification.

\section{Medical Conditions}

According to the $\mathrm{CDC}$, chronic diseases such as heart disease, cancer, cerebrovascular disease, chronic obstructive pulmonary disease, and diabetes are the leading causes of death and disability in the United States. The CDC also reported that "five chronic diseases-heart disease, cancers, stroke, chronic obstructive pulmonary diseases, and diabetes account for more than two-thirds of all deaths in the United States" (www.cdc.gov/nccdphp, retrieved 11/19/04). In a focused review, Bean, Vora, and Frontera (2004) stated, "The 5 most common chronic illnesses among older adults are arthritis, CVD, diabetes, respiratory disease, and stroke"(p. S34).

Arthritis, back problems, and heart trouble continue to be the three most common causes of disability as stated by the Morbidity \& Mortality Weekly Reports (MMWR) (www.cdc.gov/mmwr/preview, 2009).

As previously acknowledged, numerous medical conditions and poor health may involve hospitalization, therapy, and escalating health care costs. Some physicians, as well as other medical professionals, are referring their patients with medical conditions to continue care in a health club setting. Some of the major health concerns have by now been mentioned; however a review of commonly treated medical conditions will now be addressed. 


\section{Cardiovascular Disease}

Coronary heart disease, also known as coronary artery disease (CAD), is an array of illnesses or conditions affecting the heart. The coronary arteries provide oxygen and other important nutrients to the heart. Blood flow is diminished when these arteries become narrow or clogged as a result of buildup, also called "plaques". Abnormal plaque build-up from cholesterol and other fat-like substances inside the vessel wall, along with a fibrous matrix and calcium, causes the artery wall to harden resulting in atherosclerosis; this may lead to more serious conditions such as myocardial infarction in the heart and stroke in the brain. According to Gordon, Gulanick, Costa, Fletcher, Franklin, Roth, \& Shephard (2004), "Both coronary artery disease (CAD) and ischemic stroke share links to many of the same predisposing, potentially modifiable risk factors (hypertension, abnormal blood lipids and lipoproteins, cigarette smoking, physical inactivity, obesity, and diabetes mellitus), which highlights the prominent role lifestyle plays in the origin of stroke and cardiovascular disease" (p. 2031).

Grimm (1999) found that diet and exercise are key components to manage weight and reduce the incidence of Type 2 diabetes, a major risk factor contributing to higher prevalence of cardiovascular disease. According to Grimm, "Exercise and diet interventions as well can favorably influence insulin resistance, the metabolic syndrome and the associated cardiovascular risk. Dietary and exercise interventions are of high interest as they are non-pharmacologic, cheap and safe if the required recommendations before entering an exercise programme are observed" (p. 364). This article described insulin resistance syndrome and its causes, and also addressed the 
differences among common diet plans and interventions. The findings suggested weight loss and circuit-type resistance training were effective for decreasing insulin resistance and associated cardiovascular risk. Grimm (1999) reported total caloric intake has a major influence on insulin resistance and glucose intolerance.

Lavie and Milani (1997) similarly reported, "Obesity adversely affects many of the well-known CAD risk factors, including increasing levels of arterial pressure and prevalence of left ventricular hypertrophy, decreasing insulin sensitivity, adversely affecting plasma lipids (in particular decreasing levels of HDL cholesterol and increasing triglycerides), and leading to a sedentary lifestyle. In addition, data suggest that obesity is an independent CAD risk factor" (p. 399). In the article by Lavie and Milani (1997), 588 patients with CAD, and a subgroup of 235 patients classified as obese, were studied and compared before and after phase II cardiac rehabilitation and an exercise training program. The program lasted approximately three months and included supervised exercise and education sessions. Anthropometric measurements were obtained along with plasma lipids, at baseline and one week after completion. The obese subgroup had significant improvements in obesity indexes, exercise capacity, HDL cholesterol, and LDL/HDL ratio after completion of programs.

Thompson et al. (2003) also reported that physical activity reduces insulin resistance and glucose intolerance. "Physical activity both prevents and helps treat many established atherosclerotic risk factors, including elevated blood pressure, insulin resistance and glucose intolerance, elevated triglyceride concentrations, low high-density lipoprotein cholesterol (HDL-C) concentrations, and obesity" (p. 3110). 
Along the lines of physical activity and prevention, Thompson, et al. reported the need for aerobic physical activity and its many benefits on cardiovascular disease (2003). The article provided evidence that physical activity reduces the risk of chronic diseases and concluded that health professionals should recommend activity for their patients. "Health professionals should prescribe physical activity programs commensurate with those recommended by the CDC and the ACSM, i.e., 30 minutes or more of moderate-intensity physical activity such as brisk walking on most, and preferably all, days of the week"(p. 3114). The authors also stated, "Healthcare providers caring for patients with diagnosed cardiovascular disease should support the development of exercise programs to manage these patients and make appropriate referrals for treatment" (p. 3114).

As previously stated, cardiovascular disease may lead to a heart attack, if not properly treated and/or prevented. A review article by Leon (2000) addressed the many potential benefits of regular exercise and provided guidelines for exercise training for rehabilitation of post-myocardial infarction patients. The focus of the article was on prescription of exercise for patients with uncomplicated MI following hospitalization, during phases II to IV of a cardiac rehabilitation program. Phases II through IV of rehabilitation begin during the first three months after hospitalization, include exercise in supervised outpatient medical facilities, and continue through a community or home-based unsupervised "lifetime maintenance" phase. According to Leon (2000), benefits attributed to exercise training include: 1) Improvement in functional capacity and exercise tolerance, 2) Improved cardiovascular efficiency, 3) Reduction in atherogenic and thrombotic risk factors including an increase in plasma 
high density lipoprotein (HDL)-cholesterol, a decrease in plasma triglycerides, reduction in elevated blood pressure levels, improved glucose-insulin dynamics, reduced fibrinogen levels, reduced platelet aggregation to usual stimuli and increased tissue plasminogen levels" (p. 303); 4) Improvement in coronary blood flow, reduced myocardial ischaemia and severity of coronary atherosclerosis; 5) Reduction in risk of cardiovascular disease mortality; and 6) Improvement in psychosocial well-being (p. 304). Leon (2000) concluded, "Ideally, exercise conditioning of the cardiac patient begins in the hospital or shortly following discharge and continues for a lifetime, and should include cardiorespiratory endurance, muscular strength promotion and flexibility exercises" (p.310). This has been congruent with similar articles addressing exercise and cardiovascular disease including Thompson, et al. (2003), and ACSM's Guidelines (2010).

Strokes are another major health concern for individuals with cardiovascular disorders. According to Gordon, et al. (2004), "Persons who have previously had a stroke are at a markedly increased risk for a recurrent stroke. Although most strokes are potentially preventable, especially ischemic strokes, stroke remains the thirdleading cause of death in the United States"(p. 2037).

Gordon, et al. (2004) reviewed the benefits of exercise for stroke patients; indicating that the exercise trainability compares to that in healthy people of a similar age (p. 2033). The article explains the goals, effects, pre-exercise evaluation, recommendations for exercise programming, barriers, and risk reduction. According to the authors, functional effects or "impairments", such as hemiplegia, spasticity, and aphasia are the primary neurological disorders caused by stroke; and activity 
limitations, also called "disabilities" are apparent by reduced ability to perform daily functions, such as dressing or walking. The authors also noted common household tasks are correlated with greater energy demands among poststroke women than their healthy equivalents. Aerobic exercise training and improved cardiovascular fitness might enable activities of daily living to be performed at a lower percentage of the aerobic capacity (Gordon et al., 2004, p. 2033). The three major goals of rehabilitation for the stroke survivor include: initiation of physical conditioning to prevent complications of prolonged inactivity; prevention of recurrent stroke and cardiovascular events by reducing risk factors; and finally improvement in aerobic fitness. These goals are attainable and could be achieved in the health club environment with the assistance of a specialized personal trainer. The authors concluded, "Clearly, there is an urgent need to bridge the treatment gap by developing and implementing approaches that provide all stroke survivors with affordable access to effective, comprehensive stroke risk-reduction interventions" (p. 2038).

Resistance training, also known as strength training, has been shown to be beneficial in the prevention and rehabilitation of certain medical conditions. In the past resistance training was not as highly regarded as aerobic training. Today, resistance training is often a part of the exercise prescription for both cardiac and stroke patients (Gordon, Gulanick, Costa, Fletcher, Franklin, Roth, \& Shephard, 2004; Leon, 2000; and Pollock et al., 2000). Leon (2000) reported, "Muscle strength or resistance training can also be safely included in the exercise rehabilitation of clinically stable CHD patients. Resistance training has been demonstrated to result in significant improvement in muscular strength and endurance in cardiac patients" 
(p. 302). Pollock et al. (2000) stated similarly, "Many cardiac patients lack the physical strength and/or self-confidence to perform common activities of daily living. Mild-to-moderate resistance training can provide an effective method for improving muscular strength and endurance, preventing and managing a variety of chronic medical conditions, modifying coronary risk factors, and enhancing psychosocial well-being"(p. 832).

Strength training has been noted to reduce the risk of falls by increasing muscle strength and stability, increasing bone mineral density and increasing basal metabolism. Improvement in self-confidence and strength is a major benefit when working with older adults. The addition of low- or moderate-intensity resistance training may be more beneficial than previously thought, and should be a part of the exercise prescription as long as it is reviewed by medical personnel. According to Pollock, et al. (2000), resistance training can be beneficial in the prevention and management of chronic conditions as well as in rehabilitation for orthopedic injuries. This review article addressed the role of resistance training for persons with and without cardiovascular disease, including the benefits, rationale, physiological considerations, safety, participation criteria and exercise prescription. According to Gordon, et al. (2004), strength training is also beneficial for stroke patients. "Training in the performance of mobility and personal care tasks, together with attempts to improve muscle strength and coordination, continue to form the central areas of focus of most rehabilitation programs" (p. 2034). 


\section{Shoulder Injuries}

The shoulder joint is one of the most complex joints in the body, and is a common site of injury (Brunet, Norwood, \& Sykes, 1997; Donovan \& Paulos, 1995; Murrell \& Walton, 2001; Ryan, 2004). The musculature of the joint mainly consists of the rotator cuff muscles: supraspinatus, subscapularis, teres minor and infraspinatus, and also the deltoid muscle. The subscapularis internally rotates the arm; the infraspinatus and teres minor perform external rotation; and the supraspinatus with the deltoid abduct the arm. Together the rotator cuff muscles are responsible for depression and stabilization of the humeral head.

According to Murrell and Walton (2001), 50\% of major shoulder injuries are Rotator cuff tears and are sometimes difficult to diagnose. Chronic disability of the shoulder is often caused by tears of the rotator cuff muscles and frequently goes undetected in the evaluation of the shoulder (Donovan \& Paulos, 1995).

There are generally two categories of rotator cuff injuries: traumatic and overuse (Donovan \& Paulos, 1995; Ryan, 2004; Wolin \& Tarbet, 1997). As stated by Wolin and Tarbet (1997), "Several different mechanisms of rotator cuff injury are presently recognized. These can be divided into acute traumatic injuries (macrotrauma) and the more common repetitive overuse injuries (microtrauma) seen in overhead activities". This is supported by Ryan (2004), reporting, "Microtraumatic wear and tear from repetitive over-use through hyperextension arm maneuvers in, for example, sport...can cause a degenerative tendonosis that weakens the cuff tendon. Macrotraumatic forces can tear an already weakened muscle tendon...resulting in hypervascularity and inflammation" (p. 27). 
Overuse injuries of the shoulder include bursitis, tendonitis, and degenerative or post-traumatic arthritis. Issues of frequent concern are repetitive overhead activities such as swimming and throwing, or unaccustomed repetitive strenuous activity as gardening, golfing and shoveling snow. Traumatic injuries of the shoulder can be categorized as contusions, fractures, dislocation, subluxation, separation, or traumatic impingement (Donovan \& Paulos, 1995). Brunet, Norwood, \& Sykes (1997), had similar findings, indicating that the most likely diagnoses of shoulder pain are due to 1) Impingement syndrome with three stages: bursitis, tendonitis, and rotator cuff tear; 2) Shoulder instability; 3) Adhesive capsulitis, and 4) Inflammation of the acromioclavicular joint.

More recently impingement has been divided into two categories: primary and secondary. There are three classes to the primary impingement injury which include: stage one, edema and hemorrhage; stage two, with repetitive impingement, are fibrosis and tendonitis; and stage three a partial or complete tear of the rotator cuff. Secondary impingement is of a microtraumatic mechanism, people who have shoulder instability as a result of congenital laxity, repetitive microtrauma, or macrotrauma place increased demands on the rotator cuff (Wolin \& Tarbet, 1997). Continuous impingement may cause tearing of the rotator cuff tendon which causes further weakening of the rotator cuff, and in turn causes further impingement. Some factors associated with impingement are: diminished subacromial space; weakness of the rotator cuff musculature; weakness of the scapular musculature; aging of the rotator cuff tendon and repetitive overhead activity (AAHFRP manual, 2001). 
When evaluating a shoulder injury a specific test is used to assess range of motion; this test is known as the "painful arc". This test involves the patient lifting his/her arm in full abduction; pain is usually felt at 45 degrees when tissue is impinged. Generally impingement causes pain with overhead motion (Brunet, Norwood, \& Sykes, 1997; Ryan, 2004). Symptoms and presentation of rotator cuff injury consist of pain, weakness, and limited range of motion. The pain is likely to be anterior, superior, and lateral to the shoulder (Ryan, 2004; Wolin \& Tarbet, 1997). Musculoskeletal Conditions

There are an abundant array of injuries and/or diseases associated with the muscles and bones of the body. Walsh (2004) introduced the Bone and Joint Decade (BJD). Its objectives are outlined. "The BJD is a global multidisciplinary initiative that aims to reduce the burden and cost of musculoskeletal disorders to individuals, caregivers, and society" (p. 1397). The BJD encompasses diseases associated with musculoskeletal disorders such as joint diseases, osteoporosis, osteoarthritis, rheumatoid arthritis, low back pain, spinal disorders, severe trauma to the extremities, and crippling diseases and deformities in children (Walsh, 2004, p.1395). The following three sections explain some of the common musculoskeletal conditions previously mentioned.

\section{Back Injuries}

Back pain, also referred to as cervical strain or lumbar strain, is a very common medical condition seen by physicians, chiropractors and physical therapists. Gorevic (2004) reported, "Among ambulatory persons age 75 or older, back pain is the third most frequently mentioned symptom, and the most common musculoskeletal 
complaint. Low back pain is more commonly due to structural abnormalities of the spine in older persons; however systemic diseases (e.g., metastases, metabolic bone disorders) are twice as frequent a cause of low back pain in older adults and need to be considered in the differential diagnosis."

The cost burden of chronic disease in the health care systems as well as in private industry, in the way of productivity loss, is a significant burden for the U.S. and Canada (Baldwin, 2004; Keller, Ehrhardt-Schmelzer, Herda, Schmid \& Basler, 1997). Baldwin (2004) reported, "Approximately 65 to $80 \%$ of adults, including persons outside the labor force, experience one or more episodes of back pain during their lifetimes, while approximately $8 \%$ of the working-age population experiences a disabling episode of low back pain in any given year" (p. 36).

Spoelhof and Bristow (1989), indicated that physicians may come across certain "pitfalls" when diagnosing back pain. These pitfalls include: poor physicianpatient relationship (indicating patients are more satisfied with their chiropractors and receive better service than with their physicians), incomplete history; incomplete physical examination (suggesting lack of office time for appropriate examination), inappropriate use of ancillary tests, inappropriate use of analgesics, and failure to recognize an emergency. Most patients with back pain respond rapidly to treatment, some have persistent or recurrent pain (Spoelhof \& Bristow, 1989). The article later stated, "The long delay in recovery often causes frustration for both the physician and the patient. As both struggle to come to grips with the problem, often under pressure from family members and employers, medical care may become superficial or fragmented" (p.1). 
Kose and Saadet Otman (2004) stated, "Disc herniation is associated with significant impairment of physical and psychosocial functions." They went on to say, "In addition, pain is the most important reason for a low quality of life. The patient's movements become limited, inactivity occurs and physical, recreational and vocational activities are adversely affected" (p. 284).

Pain is a major influence on quality of life in terms of emotional status and physical function. Walsh and Radcliffe (2002), indicated, "The degree to which a patient believes that they are disabled by their pain is a powerful factor in the extent of their functional impairment" (p. 23). The authors also stated, "Pain beliefs may influence disability either directly, or by influencing the adoption of coping strategies (p. 23). This goes along with Keller, Ehrhardt-Schmelzer, Herda, Schmid \& Basler (1997), indicating "People who suffer from pain often fear that physical activity may increase their suffering, and therefore, avoid being active." The authors later suggested, "From a psychological perspective, avoidance behaviour results in a decrease of activities that are incompatible with pain, and thereby, to a decrease in quality of life and personal wellbeing" (p. 279). According to Walsh and Radcliffe (2002), "Changing pain beliefs may mediate reductions in disability through a variety of mechanisms, influencing patients' adoption of coping strategies and their compliance with treatment interventions" (p. 30). In this study, 84 patients were asked to respond to self-report questionnaires before, immediately after, and three months after participation in a multidisciplinary pain management program. The direction of the program was of self-management, specifically pain management. Interventions included pain and biomechanics education as well as graded exercise 
and relaxation. "Our findings indicate that beliefs about the nature and treatment of pain can change during participation in a multidisciplinary pain management programme and that changes can be maintained for at least 3 months after the end of intensive professional contact" (p. 29).

Keller, Ehrhardt-Schmelzer, Herda, Schmid, and Basler (1997) described a rehabilitation program for an outpatient group setting, addressing patients' physical functional capacity, cognitive and affective processes, and behavioral and ergonomic aspects. The treatment program included both individual and group treatments consisting of education, a reconceptualization of pain experience, and progressive muscle relaxation techniques. The authors indicated three treatment components as crucial in the prevention and treatment of chronic back pain, which include: physical exercise, training of posture and activities of daily living, and pain management ( $\mathrm{p}$. 281). Questionnaires and seven-point scales were assessment instruments. Pain frequency was reduced and posture and performance of daily activities improved. "Participation in the rehabilitation program led to statistically and clinically significant short-term improvements in almost all dependent variables compared to a waiting-list control group. Most of these improvements were maintained at 6-months follow-up" (p. 287).

An important component of chronic low back pain treatment and/or prevention consists of supervised exercise in muscle strength and flexibility. Emphasis on normal posture, i.e. neutral spine and trunk stability by means of increasing core muscle strength, is also an important factor (Keller, EhrhardtSchmelzer, Herda, Schmid, \& Basler, 1997). 
Arthritis

Arthritis is one of the most common medical conditions in the aging population, as well as in obese persons (Bean, Vora, \& Frontera, 2004; Gorevic, 2004; Suomi \& Collier, 2003). Millions of Americans are affected by arthritis. The Arthritis Foundation internet source indicates rheumatoid arthritis (RA) affects 2.1 million Americans. Nearly 21 million Americans are affected by osteoarthritis, the most common form. Osteoarthritis (OA) accounts for more than half of the total hip replacements and $85 \%$ of the total knee replacements done in the United States (Arthritis Foundation Research: RA, 2004). According to the Centers for Disease Control and Prevention (CDC), "People who are overweight are at increased risk for heart disease, high blood pressure, diabetes, arthritis-related disabilities, and some cancers."(USCDC, 2006). Gorevic (2004) reported, the risk factors for OA include age, congenital deformities, joint derangement such as meniscal disease in the knee, crystal deposition disease, obesity, and heredity.

Osteoarthritis (OA) is a very common medical condition characterized by the wearing away of cartilage and distortion or "remodeling" of the bone. "OA can result in debilitating pain and stiffness, loss of mobility and function, and eventually severe disability" (Arthritis Foundation Research: OA, 2004). Gorevic (2004) similarly stated, "OA is characterized by a slow progression, and has traditionally been considered a pain syndrome caused by mechanical derangement of the joint rather than an inflammatory disorder". In addition, Gorevic (2004) reported radiographic correlates include: loss of joint space, sclerosis, bony collapse, osteophytes, subcondral cysts, intra-articular osseous bodies, disruption and distortion of 
ligamentous structures, and deformity/malalignment. Treatment suggestions consist of patient education and reassurance, avoidance of excessive strain, strengthening the supporting muscle groups, weight loss, physical/occupational therapy, and therapy for specific joints. Clarke (1999) similarly reported, "As with RA, exercise is the only physical modality that has been consistently found to be of value in osteoarthritis (OA). Gorevic (2004) states, "OA may be accelerated in the face of trauma (especially fractures involving the joint) and when metabolic (e.g., obesity, diabetes) or neurologic disorders are comorbidities" (p. 2).

Rheumatoid Arthritis (RA) is a chronic, inflammatory disease that causes pain, stiffness, and swelling of the joints. The cartilage is destroyed by the inflamed synovial membrane. The etiology is still unknown, although environmental and genetic factors may play a role (Arthritis Foundation Research: RA, 2004).

Physical activity interventions may be a cost-effective strategy for reducing the burden of arthritis (CDC). Suomi and Collier (2003) stated, "Although research has shown that arthritic conditions can cause pain, limit daily activities, diminish measures of physical fitness, and reduce quality of life, an emerging body of evidence shows that light-to moderate-intensity physical activity may play a restorative role in combating declines in these measures caused by chronic diseases such as arthritis" (p. 1589).

In an article by Suomi and Collier (2003) guidelines were proposed by the American Geriatrics Society (AGS) for exercise plus an educational component. The purpose of their study was to determine the effectiveness of the National Arthritis Foundation (NAF) aquatic and on-land exercise programs for improvement of 
functional fitness and ability to perform activities of daily living (ADL) in older adults with arthritis (p. 1590). Participants were recruited from newspaper ads and local flyers and included both men and women between 60-79 years with diagnosed arthritis. Activities of daily living (ADL), flexibility, coordination, agility and balance, muscular strength and endurance, and cardiorespiratory endurance were measured. The intervention group was to attend community exercise classes for 8 weeks, with a minimum of 1 per week for 10 weeks; the control group was instructed to refrain from starting any new physical activity. The authors stated, "A significant finding of our study was the decreased perception of pain and difficulty in performing specific ADLs experienced by both exercise groups after the exercise intervention" (p. 1593).

A review article by Clarke (1999) addressed inflammatory and degenerative arthritis and reported exercise as the best modality for rehabilitation in arthritis. Clark also reviewed a number of studies that showed individuals suffering from RA felt less pain and had improved function after exercising.

\section{Joint Replacements}

With ongoing medical advances people are living longer. Nevertheless, more people are getting artificial joints due to pain and disease. A hip fracture meant bed rest in the 1970's; that is not the case today. "People who would have been bedridden 30 years ago now have total joint replacements that keep them moving and maintaining strength and independence" (www.physsportsmed.com/issues/2003/1203/spotlight1203.htm). 
Although joint replacements are advancing and more surgeries are taking place, there are still some complications. Wear length and infection are two major concerns (www.fda.gov, 1/13/05). The artificial joint or prosthesis is not guaranteed for life and the chance of infection increases from obtaining the prosthesis. Online sources, i.e. Yahoo!Health, www.klinikumgap.de/klinikum/en/joint_replacement_FAQ.htm, and Www.kneeclinic.info/problems_total_replacement.php, have indicated the average lifespan of an artificial joint is between 10 and 20 years. This is congruent with an FDA statement, "And a hip or knee replacement lasts at least 20 years in about 80 percent of those who get them... There may be complications. They don't always last a lifetime and when they fail, surgery may be needed" (Bren, L. www.fda.gov, retrieved 1/13/2005).

Exercise and rehabilitation for joint replacements are important issues. It has been noted that exercise after total joint replacement is beneficial in functional outcomes. Wong and Wong (1999), suggested ways to shorten hospital stays to control escalating acute care costs and focus on home or outside hospital care. The purpose of the article included: discussion of the existing discharge criteria, proposal of a scoring system for determining optimal timing of safe discharge, and implications for quality of patient care. Wong and Wong (1999) reported, "Successful recovery from total hip replacement depends largely on compliance with the prescribed home exercise regimen. . . Similar to total hip precautions, demonstration of independence in carrying out a home exercise program indicates readiness for discharge from hospital." (p. 162). The authors concluded, "The main objective of 
health care is to provide quality patient care on the one hand, and improve the efficiency of health-care services utilization on the other hand. . . Discharging patients from the acute care hospital to a home care program that mimics hospital protocols has become a feasible alternative." (p. 165).

Jan, Hung, Lin, Wang, Liu and Tang (2004) studied the effects of a home exercise program on patients after total hip replacement (THR). Patients with THP were randomly assigned to either a control or training group. The training group was further divided into exercise-high and exercise-low compliance groups. Outcome measures included strength of bilateral hip muscles, free and fast walking speeds, and functional performance. Instructions were provided to the exercise groups about how to perform the home exercises for the 12 week training period and patients received weekly telephone calls from the experimenter. The control group did not receive any instructions for the 12 week period. Results revealed subjects in the exercise-high group demonstrated significant improvements in all three measures. The exercise-low group did not show any significant changes; and the control group showed slight decreases in measurements. The authors stated, "Results of this study revealed that our home exercise program, which emphasizes hip muscle strengthening and walking exercise training, was effective in improving hip muscle strength, walking speed, and functional mobility of patients with THR. However, such positive effect was evident only if the patients had a compliance rate greater than $50 \%$ with the program" (p. 1948). "Therefore, practicing an appropriate home program could be a convenient and economical alternative for these patients to maintain muscle strength and high functional level long-term after THR" (p. 1950). 
Forrest, Roque, and Dawodu (1999) reported a reduction in orthopedic unit length of stay and an increase in admittance to rehabilitation units. "The average length of stay in 1995 was 6.4 days. The average length of stay in 1997 was 5.1 days"; the authors continued, "In 1995, 13\% of patients were admitted to rehabilitation units before returning to their homes. In 1997, 33\% of patients were admitted to rehabilitation units--a significant increase in referrals to a rehabilitation unit (p. 193). The article addressed the cost of hospital care and length of stay as compared to the cost of rehabilitation after total joint replacement. The authors examined the decreased length of stay after joint replacements and its effect on referrals for rehabilitation admission and if patient characteristics affected the need for rehabilitation. The results suggested a shift in costs of service from acute care to postacute care; and the study concluded age, comorbidity and community support affect cost of care for surgical procedures (p. 194).

Katrak, O'Connor, and Woodgate (2003) reported total femur replacement patients may need longer rehabilitation compared to total hip or knee replacements although patients with total femur replacements can attain full independence with appropriate rehabilitation. Two patients, one male and one female, both with some form of cancer/tumor who underwent total femur replacement and rehabilitation were studied. Case report descriptions from the time of diagnosis and surgery, removal of the entire femur, to rehabilitation were included. The authors noted, "A program of interdisciplinary rehabilitation is critical for achieving an optimal outcome after total femur replacement" (p. 1083). The authors concluded, "The broad principles of rehabilitation after total hip and total knee arthroplasty are applicable in patients after 
total femur replacement. These patients, however, present some special challenges because the surgery involves excision of large portions of several muscles, reattachments of these muscles, and replacement of the hip and knee joints"(p.1083) The authors finally noted that with an appropriate rehabilitation program these patients can attain satisfactory range of motion at the affected joints and a high functional independence (p. 1083). If doctors and fitness trainers working together can ward off a joint replacement, it can help save money in addition to the pain and

process. By encouraging exercise and weight reduction, health professionals can help postpone the first surgery and possibly keep the 40 or 50 year old individual from having surgery until they're 60 or 70; the results may be less hospital time and lower bills.

Fitness Programming

Lifestyle modifications including an increase in physical activity have a considerable positive influence on the above mentioned medical conditions. According to the CDC,

Regular physical activity reduces people's risk for heart attack, colon cancer, diabetes, and high blood pressure, and may reduce their risk for stroke. It also helps to control weight; contributes to healthy bones, muscles, and joints; reduces falls among older adults; helps to relieve the pain of arthritis; reduces symptoms of anxiety and depression; and is associated with fewer hospitalizations, physician visits, and medications. (www.cdc.gov/nccdphp/dnpa) 
As previously mentioned, according to the American Heart Association (AHA), the Centers for Disease Control (CDC) and the American College of Sports Medicine (ACSM), individuals should engage in 30 minutes or more of moderateintensity physical activity on most (preferably all) days of the week. The 1995 public health recommendation has since been updated. The ACSM and the AHA have released new 2008 recommendations for adults (Haskell et al., 2007). The major change is the addition of "vigorous-intensity" aerobic activity and stating 5 days a week instead of the former, more confusing version of most (preferably all) days of the week.

Information from the review of articles identifies low-to moderate-intensity exercise from $30 \%$ to $60 \%$ of $\mathrm{VO}_{2}$ max; and vigorous-intensity or high-intensity as $60 \%$ and higher (Gordon, Gulanick, Costa, Fletcher, Franklin, Roth, \& Shephard, 2004; Leon, 2000; Pollock et al., 2000). According to the ACSM Guidelines (2010), "Exercise of at least moderate intensity (i.e., $40 \%$ to $<60 \% \mathrm{VO}_{2} \mathrm{R}$ that noticeably increases $\mathrm{HR}$ and breathing) is recommended as the minimum exercise intensity for adults to achieve health/fitness benefits. However, a combination of moderate- and vigorous-intensity $\left(\geq 60 \% \mathrm{VO}_{2} \mathrm{R}\right.$ that results in substantial increases in $\mathrm{HR}$ and breathing) exercise is ideal for the attainment of improvements in health/fitness in most adults" (p. 155). Articles also show congruency indicating warm-up, cardiorespiratory, flexibility and possibly strength training, and finishing with a cooldown as parts of an exercise program. Variability of the exercise program depends on the specific medical condition- cardiovascular versus musculoskeletal, and the goals of each medical professional. 
Post-rehabilitation programs are for those individuals who have been released/ discharged from medical services that may still experience symptoms of disease and/or disability, but lack the skills needed to continue on their own. In order for medical-fitness collaboration to occur the facility needs to be prepared and relationships made. Is there a need in the community? Such information is necessary to determine the outcome.

\section{Demographics}

Demographics are necessary to define the target market. Industry data revealed about half of all health/fitness facility members are older than 35 years (IHRSA www.cms.ihrsa.org, 2002). And the fastest growing age segment among gym members is persons over age 55 (IHRSA, 2002). The San Luis Obispo County 2000 census revealed $14.5 \%$ of the population as 65 years and over, higher than the national 12.4\%. The Arroyo Grande, California, census stated the median age as 41.9, with the U.S. average of 35 years. Approximately $20 \%$ of the population in the Arroyo Grande community is 65 years or older compared to $12.4 \%$, nationally.

Kennedy Club Fitness is a family-oriented environment that includes a range of ages and needs. Demographics in the Arroyo Grande club consist mainly of the adult population. With older adults entering the fitness market such facilities need to be prepared to take on the new clientele.

In summary, supervised exercise programs referred by medical professionals may be essential in promoting optimum health and/or recovery. Physical activity; cardiovascular, strength training and flexibility, is beneficial in the prevention and in some cases treatment of many health conditions. The concept of medically-based 
fitness centers is increasing which allows health clubs and the personal trainers to assist in recovery and a more smooth transition from rehabilitation. 


\section{Chapter 3}

Methods and Procedures

\section{$\underline{\text { Restatement of the Purpose }}$}

The purpose of the project was to evaluate the current necessity and variability of post-rehab programs and to develop a Post-Rehabilitation Conditioning Program for Kennedy Club Fitness, Arroyo Grande, California.

$\underline{\text { Design }}$

A needs assessment was conducted through a review of relevant literature and interviews. A survey was conducted to obtain information on which to base this project. The purpose was not to identify cause and effect, but rather to establish a basis for an effective post-rehabilitation program.

\section{$\underline{\text { Subjects }}$}

The population for this research project included 88 local medical professionals: physicians, physical therapists, and chiropractors in the Arroyo Grande area, of San Luis Obispo County, CA; and two volunteer Kennedy Club Fitness staff (See Appendix A). Prospective subjects were entered into an Excel Spreadsheet and the database was cross referenced with yellowpages.com internet source.

\section{$\underline{\text { Procedures }}$}

\section{$\underline{\text { Needs Assessment }}$}

Between December, 2004, and March, 2006, a needs assessment was conducted through a review of relevant literature; government websites, professional organizations and journal archives along with other sources such as websites, online 
publications, and interviews with medical professionals in the community. Local demographics were examined between December, 2004, and January, 2005.

Pilot Testing Informal Interviews: December 2004- January 2005

Informal telephone interviews consisting of four questions to local medical professionals with pre-existing associations with Kennedy Club Fitness took place during the months of December, 2004, and January, 2005. The questions were: 1. What are the 3-5 most common medical conditions treated in your facility? 2. Of those conditions, which would you refer to a local health club offering a Post-rehab conditioning program? 3. Have you ever referred patients to a Post-rehab program at a fitness facility/health club? 4. What criteria and qualifications are you looking for in a personal trainer that would make you feel comfortable about referring a patient to him/her for post-rehab activities?

Medical professionals from three different categories: Physician/MD, Chiropractor, and Physical Therapist, were contacted via phone and asked the same four questions regarding commonly treated medical conditions and referral to local health clubs. Answers were written on a separate interview sheet for each professional. After these pilot interviews a fifth question was added to the survey: Question 5. Do you have any concerns or reservations about referring to a trainer in a health club?

\section{Survey}

Approval for this research was obtained from the Cal Poly Human Subjects Committee on January 4, 2006. The refined telephone survey developed by the researcher, consisting of five questions pertaining to commonly treated medical 
conditions and referral to local health clubs, was administered to the medical professionals identified in Appendix A between January and February, 2006. At the start of each interview, an informed consent form was read (see Appendix B) and volunteer status was established. Every interview was recorded on a separate sheet by the researcher (see Appendix C). Identification was not collected on the interview sheet. Each interviewee was identified numerically. Prospective subjects were contacted one by one from the Excel spreadsheet. Each interview lasted approximately ten minutes. If the medical professional was not available, e.g. busy with patient or business was closed; the interview was tried again the following business day.

\section{Data Analysis}

An Excel worksheet was created for each of the questions asked in the interview. Pertinent information was organized by placing statements into categories to identify common themes. Raw data were entered into Excel and coding began. Each row of the worksheet was an individual's response to the question, and key words that related to the themes that emerged. After initial coding was completed verification was established by an external reader, not involved in the study, to ensure credibility. The external reader was able to take the information and categorize it. Once categories for each question were established each theme was tallied. The data were sorted to get a sense of the frequency with which people responded to questions based on the themes identified. 


\section{$\underline{\text { Program }}$}

After the literature review was complete and interviews were compiled and synthesized, a post-rehab program was produced. The researcher developed a program protocol along with fitness programs for three specific medical conditions based on survey results. A plan was derived to introduce a Post-rehabilitation conditioning program into the club (Appendix D). A copy was then given to professionals in this field of interest for review; specifically a personal trainer, the fitness director and a local chiropractor, all previously known by the researcher, were asked to evaluate a copy.

In May, 2006, free health lectures/clinics for club members and their guests were organized by the researcher and held in Kennedy Club Fitness at the Arroyo Grande location. The purpose of the clinics was for community outreach; to collaborate with local medical professionals, build a referral source and to increase awareness and communicate valuable health information to the public. The researcher contacted the professionals and asked if they would be interested in participating in the clinics. Flyers were made and distributed in the club to advertise the clinics. Each clinic lasted approximately one hour and was presented by club staff and/or local medical professionals currently associated with Kennedy Club Fitness. The three clinic topics were chosen based on the survey results and included:

1. A Low Back Care Clinic was given by a local physical therapist and club member. Subject matter discussed included acute and chronic low back pain, flexibility, and the importance of abdominal strength. 
2. A Nutrition Seminar was presented by a Kennedy Club Fitness staff personal trainer and nutritionist. Healthy eating habits and serving size were some of the topics discussed.

3. A demonstration of Proper use of Weight Machines and Precautions for a Shoulder Patient was given by a local orthopedic surgeon and club member to personal training staff. The physician gave a brief lecture and then led the trainers around the club pointing out machines of interest, likes and dislikes for a shoulder patient. 


\section{Chapter 4}

Results and Discussion

\section{$\underline{\text { Results }}$}

\section{$\underline{\text { Pilot-test Interviews }}$}

Five pilot-test phone interviews were completed between December, 2004, and January, 2005. Two physical therapists and two chiropractors were interviewed, however only one physician was available.

Both the physical therapists' and chiropractors' answers to the first two questions were general in nature. Specific diagnoses were not given as responses to questions \#1 \& \#2, regarding commonly treated medical conditions, unless prompted. Most answers were stated as a part/region of the body. The chiropractors' and physical therapists' answers were geared toward musculoskeletal problems, e.g. joint pain and degenerative disk disorder. The medical doctor answered more specifically with medical conditions such as hypertension and diabetes. Answers to question \#2 specified a deconditioned individual or musculoskeletal injury that would benefit from strengthening and flexibility exercises. The answer to question \#3 was "yes" for all interviewees, indicating they had referred someone to a fitness facility/health club. Certification names or specific degrees were not given for question \#4. "Knowledge" was mentioned as well as understanding of anatomy and physiology. All five interviewees stated they would "like to know", "have met" the trainer prior to referral. Understanding of the medical professionals' goals and giving congruent information was of high importance. 


\section{Demographics of Club Members}

Demographics in the Arroyo Grande club consisted mainly of the adult population. Information obtained from the membership department in 2004 revealed member totals of 3,285. The age range of 30-49 years included 1408 (43\% total membership) and ages 50-102 included 897 (27\% of total membership) with the remaining members between 16 and 29 years of age. This indicated $70 \%$ of the club members were older than 30 , which was congruent with industry research stating that about half of all health/fitness facility members are older than 35 years, and the fastest growing age segment is 55 and over (www.cms.ihrsa.org/index, 2002).

\section{$\underline{\text { Survey Results }}$}

Eighteen out of 88 possible interviews were successful, a $20 \%$ response rate; four physicians, four physical therapists, and ten chiropractors. The pilot-test interviews were not pooled with the sample, I did not want to double count any interviews. Survey results revealed the most common medical conditions to be referred to a health club in the Arroyo Grande area would be musculoskeletal in nature, i.e. joint pain. Table 1 presents the results of the survey. From those 18 interviews the five most common medical conditions treated (question \#1) included: neck, low back, headache, shoulder, and back. In response to question \#2, of those conditions which would be referred, answers included low back, neck and shoulder. To Question \#3, regarding referral in the past to health clubs, 11 subjects said "yes" and 7 responded "no". Answers to question \#4 regarding criteria/qualifications of a personal trainer included: knowledge, training experience, case knowledge, certification, relationship, technique, manners, and reputation. In response to question 
\#5, concerns regarding referring to a health club, 13 responded "yes" with some side notes like "if change the plan" or "exacerbate the problem", and the remaining 4 did not have concerns.

Table 1

Survey Results

\begin{tabular}{|l|l|}
\hline Question 1 & TOTAL \\
\hline Neck & 10 \\
\hline Low Back & 9 \\
\hline Headache & 7 \\
\hline Shoulder & 6 \\
\hline Back & 4 \\
\hline Knee & 3 \\
\hline Diabetes & 3 \\
\hline Wrist & 2 \\
\hline Cancer & 2 \\
\hline $\begin{array}{l}\text { Hormonal } \\
\text { Imbalances }\end{array}$ & 1 \\
\hline Metal Toxicity & 1 \\
\hline $\begin{array}{l}\text { Adrenal } \\
\text { Fatigue }\end{array}$ & 1 \\
\hline Respiratory & 1 \\
\hline Postural & 1 \\
\hline Balance & 1 \\
\hline Sports Injuries & 1 \\
\hline Subluxation & 1 \\
\hline $\begin{array}{l}\text { Postpolio } \\
\text { Syndrome }\end{array}$ & 1 \\
\hline Alzheimers & 1 \\
\hline Stroke & 1 \\
\hline Dementia & 1 \\
\hline Hypertension & 1 \\
\hline Skin Conditions & 1 \\
\hline Infections & 1 \\
\hline Hernia & 1 \\
\hline Gallstone & 1 \\
\hline Arthritis & 1 \\
\hline ('TOtal' & 14 ts \\
\hline
\end{tabular}

\begin{tabular}{|l|l|}
\hline Question 2 & TOTAL \\
\hline Low Back & 9 \\
\hline Neck & 5 \\
\hline Shoulder & 5 \\
\hline Back & 3 \\
\hline Knee & 3 \\
\hline Diabetes & 3 \\
\hline Hypertension & 1 \\
\hline Balance & 1 \\
\hline Stroke & 1 \\
\hline $\begin{array}{l}\text { Hormonal } \\
\text { Imbalances }\end{array}$ & 1 \\
\hline Sports Injuries & 1 \\
\hline $\begin{array}{l}\text { Adrenal } \\
\text { Fatigue }\end{array}$ & 1 \\
\hline Headache & 1 \\
\hline Wrist & 1 \\
\hline Arthritis & 1 \\
\hline Respiratory & 0 \\
\hline Subluxation & 0 \\
\hline $\begin{array}{l}\text { Postpolio } \\
\text { Syndrome }\end{array}$ & 0 \\
\hline Alzheimers & 0 \\
\hline Postural & 0 \\
\hline Dementia & 0 \\
\hline Infections & 0 \\
\hline Skin Conditions & 0 \\
\hline Cancer & 0 \\
\hline Hernia & 0 \\
\hline Gallstone & 0 \\
\hline Metal Toxicity & 0 \\
\hline
\end{tabular}

\begin{tabular}{|l|l|}
\hline Question 3 & TOTAL \\
\hline Yes & 11 \\
\hline No & 7 \\
\hline
\end{tabular}

\begin{tabular}{|l|l|}
\hline Question 4 & TOTAL \\
\hline Knowledge & 11 \\
\hline $\begin{array}{l}\text { Training } \\
\text { (Hands on) }\end{array}$ & 10 \\
\hline $\begin{array}{l}\text { Case } \\
\text { Knowledge }\end{array}$ & 9 \\
\hline Certification & 6 \\
\hline $\begin{array}{l}\text { Phys./Trainer } \\
\text { Relationship }\end{array}$ & 5 \\
\hline Technique & 4 \\
\hline $\begin{array}{l}\text { Manners / } \\
\text { Personality }\end{array}$ & 3 \\
\hline Reputation & 1 \\
\hline
\end{tabular}

\begin{tabular}{|l|l|}
\hline Question 5 & TOTAL \\
\hline Yes & 13 \\
\hline No & 4 \\
\hline No response & 1 \\
\hline
\end{tabular}

("Total" is the number of responses)

\section{Program}

Based on the needs assessment a program was designed. Post-rehab conditioning programs encompass: certification, collaboration with the medical community, and a systematic protocol. Fitness assessments, exercise programming 
and documentation to the medical authority comprise important parts of post-rehab programs, along with health promotion programs. A plan for a post-rehabilitation conditioning program was developed in conjunction with three fitness guidelines based on the survey results. A flow chart was created to indicate the program process (see Figure 1).

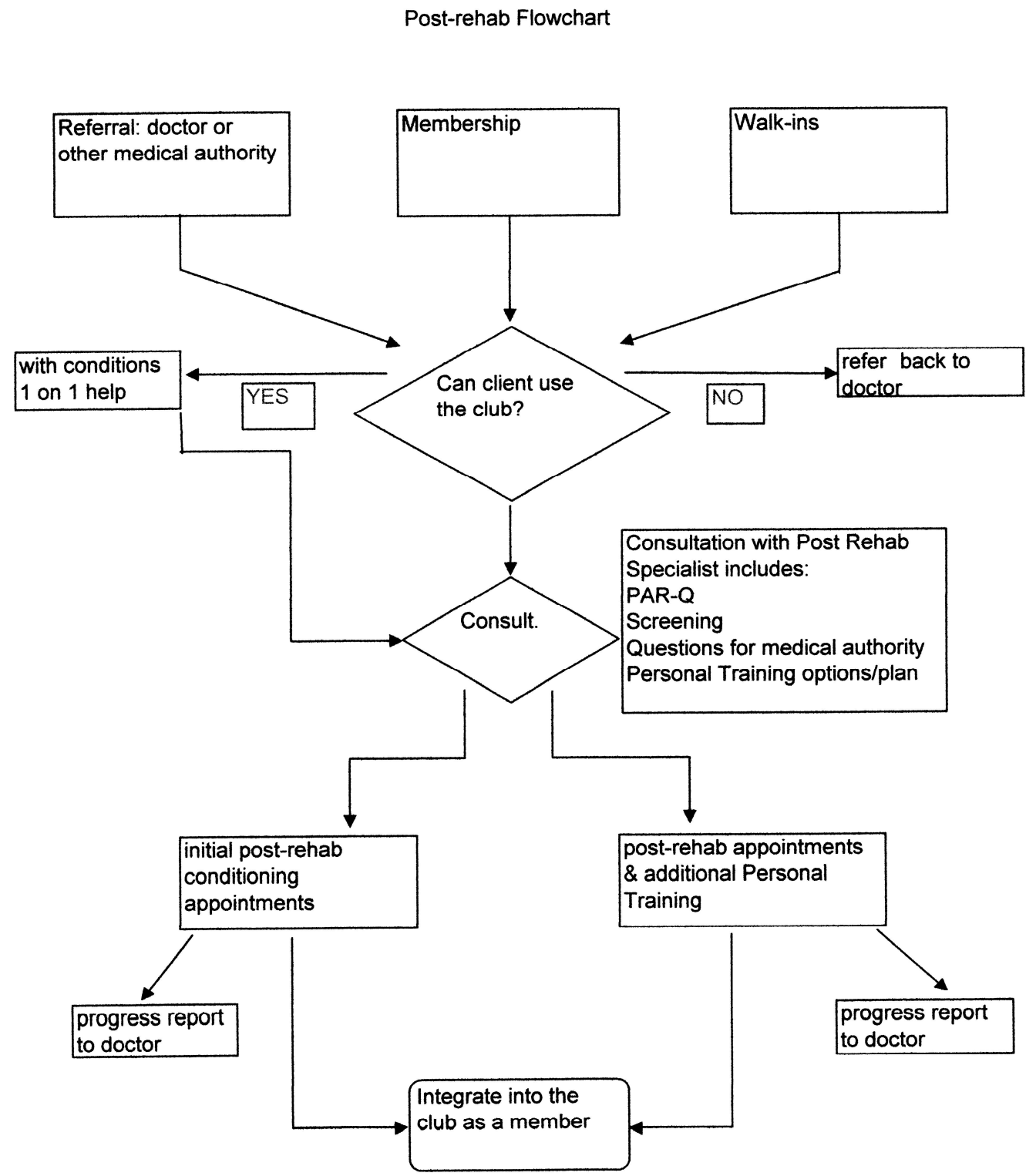

Figure 1. Flow Chart 
The Post-rehab Conditioning Program was comprised of a trial membership in the club by referral from a medical professional, an initial consultation with a Postrehab certified trainer, conditioning appointments to establish the exercise plan, progress reports to the referring medical professional and free health clinics (see Appendix E). The initial consultation encompassed the PAR-Q form (Canadian Society for Exercise Physiology), the Lifestyle Assessment Questionnaire (medical history, health \& nutrition, lifestyle habits), Fitness Assessment (all from Fitness Publisher software used in the club) and the addition of a Musculoskeletal Screening, based on information from the AAHFRP certification manual (see Appendix F). An example of the Post-rehab program process for a client with low back pain is as follows: Step 1. Greet the new client at the front desk/lobby of the club. The client should have the referral slip from their medical authority. Take the client to the consultation/fitness assessment room. Step 2. The consultation process begins with the Client Data Questionnaire/emergency contact information, and proceeds with the PAR-Q form and Lifestyle Assessment Questionnaire to obtain medical history and lifestyle habits. Review of the referral sheet and client's complaints and goals are identified. This takes approximately 30 minutes, half of the one-hour consultation. Once all paperwork is complete the Fitness Assessment process begins. Step 3. Seated heart rate and blood pressure are taken by an electronic blood pressure device with the client's arm resting on either the desk or arm of chair. Height and weight are followed by circumference measurements of the chest, upper arm, waist, hips, thigh, and calf using a spring loaded tape measure. Flexibility is assessed using the sit and reach test for trunk flexibility. The AAHFRP Musculoskeletal Screening, of numbers 
1 and 8-10 for a low back client which are "Postural Screen", "Single Knee to Chest", "Hamstring Flexibility", and "Balance", completes the consultation process. Step 4. If no "red flags" are apparent proceed to Conditioning appointments. The first fitness appointment is scheduled and the exercise plan prepared and faxed to the medical professional. Step 5. The first Conditioning appointment is used to familiarize the new client with the cardio machines and begin the new exercise plan. (The first three weeks of the program focus on flexibility, spinal stabilization activities and some upper and lower extremity strengthening). First, the low back client performs a five minute warm-up using a recumbent bike as well as 5 minutes on an elliptical or treadmill machine, to learn the buttons and necessary adjustments. Step 6. Following the warm-up, seated stability ball exercises are introduced such as pelvic tilts and hip rotation for low back pain relief and flexibility. Further flexibility exercises are introduced including: Piriformis/ Figure 4 stretch, Cat stretch on all fours, seated hamstring stretch, and supine cross-over stretch. Hip bridges and core/abdominal exercises are also established. Step 7. At the conclusion of the first appointment, the second appointment is scheduled and the client is encouraged to participate in some appropriate group exercise classes and to utilize the pool. Step 8 . The second fitness appointment includes the introduction to certain exercises for low back care such as, leg press, rowing, chest press, leg extension/leg curl, and lateral raise. Step 9. And a review of the exercises covered during the first fitness appointment. All exercises are supervised by a Post-rehab trainer and recorded on a training card for the client. (If further instruction is needed the client may request additional sessions with the trainer.) Following the second appointment a 3-week progress report/assessment is 
scheduled. Step 10. The completed progress report is then sent to the referring medical authority for review. Step 11 . The client continues with the program and becomes more actively involved in the club, for instance attending the health lectures and participating in water aerobics. At the end of the 3-month trial membership the client then has the option to join the club as a regular member.

Free lectures/clinics for club members were organized by the researcher and presented by personal training staff and local medical professionals for the purpose of collaborating with the medical community and as a marketing strategy. The three topics of interest: low back care, nutrition/weight management and shoulder complications, were chosen based on the survey results and the high incidence of these conditions.

The Low Back Care clinic was given by Shelly Allis, a local physical therapist, who discussed issues such as acute/chronic LB pain, flexibility and the importance of abdominal strength. The Nutrition seminar was given by a Kennedy Club Fitness personal trainer and certified nutritionist, Ginger Lordus. Information covered in this seminar included healthy eating habits, healthy snack ideas and serving sizes with actual food items as visual aids (Appendix G).

The Shoulder clinic was not open to members but used as an educational tool for club staff. A demonstration of proper use of exercise machines and precautions for a shoulder patient was given by a local orthopedic surgeon and club member to the personal training staff. The physician gave a brief lecture on shoulder structure and injury and then walked around the club pointing out machines of interest, and indicated and contraindicated exercises for a shoulder patient. 
In conjunction with the Fitness Director/Boss some marketing materials were made; brochure and club passes, (see Appendix H) but unfortunately the program never fully developed. The club had other priorities and time and money were not allotted for the project. Trainers were encouraged to seek advanced certification but this was not mandated or organized.

\section{$\underline{\text { Discussion }}$}

It was easier to get physical therapists and chiropractors on the phone to answer the survey than physicians. This might explain the majority of reported conditions as musculoskeletal rather than cardiovascular or metabolic. The low response rate indicates the professionals did not have time to talk on the phone, and in the future surveys may have a greater response rate if faxed or filled out by the office staff. The lack of responses might be attributed to the unfamiliar surveyor on the phone and/or calling during business hours. Perhaps in-person interviews would be a better option to increase response rate. The survey provided information regarding the types of conditions to be referred to the club, as well as if the local medical professionals had thought about using the health club as a resource. The implications of the survey are that medical professionals are hesitant to use a gym/club for followup treatment, suggesting there is distrust of gyms and trainers. Advanced certification and building relationships might defeat that notion. The survey helped determine what qualifications and/or certification the medical professionals would be looking for in a personal trainer. There was not one set certification/agency of specific interest. The medical professionals were interested in communication and mutual understanding of the patients'/clients' needs. The needs assessment helped to 
establish the parts of the program; the consultation process, length of membership and to whom the program should be available, as well as inclusion of a health promotion option such as seminars. Through the examined literature Post-rehab programs varied by type of company, hospital or fitness facility; length of membership (month-tomonth, 3 month or 6 month); the number of supervised training sessions; and cost/fees of the program. However, a similar concept between programs was a referral/medical clearance for entry into the program and a consultation or fitness assessment.

Analysis of the data posed a problem in that a computer software program was unavailable. A qualitative analysis program (QSR-NUDIST) was offered to the researcher. However, by the time surveys were completed it was not accessible. Therefore the researcher had to analyze the data the "old fashioned" way by searching for common themes and putting them into an excel spreadsheet for numerical data. This took longer than expected. A semi-structured survey was used to allow the medical professionals to answer more freely; express their opinions. It may have been easier to use a closed-question survey; however, the goal was for medical professionals to answer without being prompted and to express desires and opinions. Another set-back and limitation was support for further development. The club had other priorities and time and money were not allotted for this project. A goal was to have Kennedy Club Fitness host the certification workshop necessary for the AAHFRP Post-rehab certification and to certify as many trainers as possible, at least half of the twelve personal trainers already employed by Kennedy Club Fitness. 
Without the advanced certification there would not be much to market or network to the community.

The set-up of the program was based on several factors, such as existing programs and prior education and experience. Concepts were used from other programs and put together in order to provide what the doctors/medical professionals might need. The intention was to provide services to the de-conditioned and/or at-risk population by working together with the medical community. Therefore it is imperative to have an open line of communication between the medical professional, the client and the personal trainer, to build trust and establish the appropriate conditioning program. Documentation and reporting to the medical authority helps to maintain a cohesive program and assists in liability.

A copy of the program was distributed to three professionals for review. According to professional review of the program it was satisfactory and insightful. They felt there would need to be more concrete steps to the program, pricing and club logistics as well as professional marketing materials, but all in all it was a good endeavor. They found it exciting to get the community involved in an establishment that was already highly respected. In regard to the clinics, attendance seemed low with approximately 7-10 people. This may be due to the 12:00 noon time slot or not enough advertising or membership awareness.

A goal of a Post-Rehabilitation Program in Kennedy Club Fitness was to partner with the medical community to promote physical activity and increase information at the community level. This was not fully accomplished, however currently efforts are being made. Over the years more personal trainers have earned 
advanced Post-rehabilitation Conditioning Specialist certifications from AAHFRP and the club has selected a representative for networking requirements. Since this project and surveys were conducted new marketing materials were made and a representative, the former Fitness Director, was able to establish community collaboration between Kennedy Club Fitness and local hospitals, offices and clinics. 


\section{Chapter 5}

Summary, Conclusions and Recommendations

\section{Summary}

Physical inactivity is a major health problem in the United States. More than $50 \%$ of American adults are not regularly physically active. Moreover, physical activity is beneficial in the treatment of persons with chronic disease and disability (ACSM's Guidelines, 2010; NCCDPHP, 2004). The purpose of this project was to develop a post-rehabilitation conditioning program for Kennedy Club Fitness, and evaluate the current necessity and variability of post-rehab programs. A needs assessment was completed through a review of relevant literature; government websites, professional organizations and journal archives, along with other sources such as websites, online publications, and interviews with local medical professionals. Results from a telephone survey regarding commonly treated medical conditions and referral to health clubs were compiled and synthesized. A Post-rehab program was designed and provided to Kennedy Club Fitness staff in May of 2006 in hopes of expansion of personal training and establishing a community medical network.

\section{Conclusions}

1. The necessity for post-rehab programs is to continue the course of rehabilitation which allows for a more smooth transition from rehab to fitness and wellness, and also to partner with the medical community to offer more resources that promote a healthy and active lifestyle for all populations. 
2. Variability of post-rehab programs is decided by the facility/company; for instance length of membership (month-to-month or 3 month), program options (number of training sessions and equipment), cost, and goals. Also, variability of post-rehab conditioning programs depends on the goals of the medical authority and each client's/patient's needs.

\section{$\underline{\text { Recommendations }}$}

1. The researcher recommends the organization of a dedicated team/key staff (a Post-rehab entity within the club) consisting of a director/appointment manager (to bypass the front desk staff scheduling appointments), multiple Post-rehab certified trainers to allot for personal training time as well as consultations, and a marketing representative.

2. Expectations and goals of the facility/health club should be made up front so that all staff are on the same page to reduce setbacks.

3. High-quality, easy to read marketing materials for distribution should be given only to those supportive of the program, with-in network, and not mass distributed. Therefore, the focus is on a key group of medical professionals to build the relationship rather than neglect a referral source.

4. For future surveys to medical professionals, the researcher recommends mailers or faxed versions to be filled out by office/administrative staff or the medical professional for a higher response rate.

5. In-person interviews with the medical professionals would make it more personable which may increase the response rate. 
6. Future students are encouraged to carry out site visitations and/or interview existing Post-rehab programs to gain further insights (successes and failures) of said programs.

7. For increased community collaboration and awareness the facility should become a member of the Medical Fitness Association (MFA).

8. Quarterly meetings among the medical community (referral sources) and the Post-rehab facility are recommended to keep the lines of communication open, and to gather what the medical professionals need from a fitness provider. 


\section{References}

AFPA Post Rehab Exercise Certification. Retrieved 5/24/2004. www.afpafitness.com/post_rehab.htm.

American College of Sports Medicine. (2000). ACSM's Guidelines for Exercise Testing and Prescription. $6^{\text {th }}$ edition. B. A. Franklin, M. H. Whaley, \& E. T. Howley (Eds.). Baltimore: Lippincott Williams \& Wilkins.

American College of Sports Medicine. (2010). ACSM's Guidelines for Exercise Testing and Prescription. $8^{\text {th }}$ edition. W. R. Thompson, N. F. Gordon, \& L. S. Pescatello (Eds.) Baltimore: Lippincott Williams \& Wilkins. Arthritis Foundation. (2004). Web Site: Arthritis Foundation Research: Rheumatoid Arthritis, Retrieved 1/10/05 www.arthritis.org/research/research_program/RA/default.asp. Arthritis Foundation Research: Osteoarthritis Retrieved 1/10/05 www.arthritis.org/research/research_program/Osteoarthritis/treatment.asp.

Baldwin, M. (2004). Reducing the costs of work-related musculoskeletal disorders: targeting strategies to chronic disability cases, Journal of Electromyography and Kinesiology, 14, 33-41.

Bean, J., Vora, A., \& Frontera, W. (2004). Benefits of Exercise for CommunityDwelling Older Adults, Archives of Physical Medicine and Rehabilitation, 85, (Suppl 3), S31-42. Focused Review.

Berry, J. (2003). Pointing to Prevention, Rehab Management- The Interdisciplinary Journal of Rehabilitation. www.rehabpup.com/features/1022003/8.asp. Retrieved 1/3/2005. 
Branzel, L. (2001-2002). Medically-Based Fitness Centers \& Post-Rehab Programs, Occupational Health Tracker- Journal of Trends \& Strategies for OccupationalHealth Professionals, 4, (4). Retrieved 11/22/2004 www.systoc.com/Tracker/Winter01/PostRehab.asp.

Bren, L. Joint replacement: An inside look. FDA Consumer Magazine, March-April 2004. www.fda.gov/fdac/features/ 2004/204_joints.html. Retrieved 1/13/2005

Brunet, M.E., Norwood, L. \& Sykes, T. (1997). What to do for the painful shoulder, Patient Care, 31, 1, 56 (16).

Canadian Society for Exercise Physiology (CSEP), PAR-Q \& You. Canadian Society for Exercise Physiology, 2002. http://www.csep.ca/english/view.asp?x=1

Cherry, D., Hing, E., Woodwell, D., \& Rechtsteiner, E., (2008) National Ambulatory Medical Care Survey: 2006 Summary, National Health Statistic Report [DHHS] www.cdc.gov/nchs/data/nhsr, Retrieved 3/20/2009

Clarke, A. (1999). Effectiveness of rehabilitation in arthritis, Clinical Rehabilitation, 13, (supp 1), 51-62.

Donovan, P., \& Paulos, L. (1995). Common injuries of the shoulder: diagnosis and treatment [Electronic version]. The Western Journal of Medicine, 163, 4, $351(9)$.

Forrest, G., Roque, J., Dawodu, S. (1999). Decreasing Length of Stay After Total Joint Arthroplasty: Effect on Referrals to Rehabilitation Units, Archives of Physical Medicine and Rehabilitation, 80, (2), 192-194.

Gill, T., Baker, D., Gottschalk, M., Peduzzi, P., Allore, H., \& Van Ness, P. (2004). A Prehabilitation Program for the Prevention of Functional Decline: Effect on 
Higher-Level Physical Function, Archives of Physical Medicine and Rehabilitation, 85, 1043-1049.

Gordon, N., Gulanick, M., Costa, F., Fletcher, G., Franklin, B., Roth, E., \& Shephard, T. (2004). Physical Activity and Exercise Recommendations for Stroke Survivors: AHA Scientific Statement, Circulation, 109, 2031-2041.

Gorevic, P. D. (2004). Osteoarthritis: a review of musculoskeletal aging and treatment issues in geriatric patients, Geriatrics, 59, (8), 28.

Grimm, J. (1999). Interaction of physical activity and diet: implications for insulinglucose dynamics, Public Health Nutrition, 2, (3a), 363-368.

Haskell, W. et al., (2007). Physical Activity and Public Health: Updated Recommendation for Adults From the American College of Sports Medicine and the American Heart Association, Medicine and Science in Sports and Exercise, 39, (8), 1423-1434.

International Health, Racquet \& Sports Club Association (IHRSA) Did you know? (2002) http://cms.ihrsa.org/index Retrieved 3/20/2009

Jan, M., Hung, J., Lin, J., Wang, S., Liu, T., Tang, P. (2004). Effects of a home program on strength, walking speed, and function after total hip replacement, Archives of Physical Medicine and Rehabilitation, 85, (12), 1943-1951.

Japsen, B. (1996). Focus on Fitness: hospitals promote their health clubs as another service in care continuum. Modern Healthcare, 26, (15), 38(4).

Katrak, P, O'Connor, B., \& Woodgate, I. (2003). Rehabilitation After Total Femur Replacement: A Report of 2 Cases, Archives of Physical Medicine and Rehabilitation, 84, 1080-1084. 
Keller, S., Ehrhardt-Schmelzer, S., Herda, C., Schmid, S., \& Basler, H-D. (1997). Multidisciplinary rehabilitation for chronic back pain in an outpatient setting: a controlled randomized trial, European Journal of Pain, 1. 279-292.

Kose, N., \& Saadet Otman, A. (2004). Comparison of the quality of life of patients with lumbar and cervical disc herniation, The Pain Clinic, 16, (3), 281-286.

Lavie, C., \& Milani, R. (1997). Effects of Cardiac Rehabilitation, Exercise Training, and Weight Reduction on Exercise Capacity, Coronary Risk Factors, Behavioral Characteristics, and Quality of Life in Obese Coronary Patients, American Journal Cardiology, 79, 397-401.

Leon, A. (2000). Exercise Following Myocardial Infarction: Current Recommendations, Sports Medicine, 29, (5), 301-311.

Levinger, I., Bronks, R., Cody, D., Linton, I., \& Davie, A. (2004). Resistance training for chronic heart failure patients on beta blocker medications, International Journal of Cardiology, 102, 493-499.

Michael K. Jones, AAHFRP www.medicalexercisespecialist.com/about.htm, Retrieved 9/28/2004.

Murrell, G., \& Walton, J. (2001). Diagnosis of rotator cuff tears, The Lancet, 357, 769-770.

National Center for Chronic Disease Prevention and Health Promotion. (2004). Physical Activity and Good Nutrition: Essential Elements to Prevent Chronic Diseases and Obesity. Retrieved 11/19/2004 http://www.cdc.gov/nccdphp/dnpa 
Ory, M. G., Yuma, P. J., Hurwicz, M.-L, Jarvis, C., Barron, K. L., Tai-Seale, T., TaiSeale, M., Patel, D., Hackethorn, D., Bramson, R. et al. (2006). Prevalence and correlates of doctor-geriatric patient lifestyle discussions: Analysis of ADEPT videotapes, Preventive Medicine, 43, 494-497.

Page, P. (2005). Working with your local physicians, The Journal on Active Aging, Sept/Oct 2005, 44-47.

Pollock, M., Franklin, B., Balady, G. et al. (2000). AHA Scientific Statement: Resistance Exercise in Individuals With and Without Cardiovascular disease, Circulation, 101, 828-833.

Rex Health Care. www.rexatwork.com/centers/wellness/index_wellness.htm. Retrieved 5/24/04.

Ryan, A. (2004). Partial Rotator Cuff Tears, Emergency Nurse, 12, (4), 27-37.

Schnirring, L. (2000). Referring Patients to Personal Trainers: Benefits and Pitfalls, The Physician and Sportsmedicine: News Briefs, 28, (1). Retrieved 9/15/04 www.physsportsmed.com/issues/2000/01_00/news.htm.

Smitherman, T. A., Kendzor, D. E., Grothe, K. B., \& Dubbert, P. M. (2007). State of the art review: Promoting physical activity in primary care settings. A review of cognitive and behavioral strategies, American Journal of Lifestyle Medicine, 1, (5), 397.

Spoelhof, G. D., \& Bristow, M. (1989). Back pain pitfalls, American Family Physician, 40, (4), 133(6).

Suomi, R., \& Collier, D. (2003). Effects of Arthritis Exercise Programs on Functional Fitness and Perceived Activities of Daily Living Measures in Older Adults 
with Arthritis, Archives of Physical Medicine and Rehabilitation, 84, 15891594.

Thompson, P. D., Buchner, D., Pina, I., Balady, G. et al. (2003). AHA Scientific Statement. Exercise and Physical Activity in the Prevention and Treatment of Atherosclerotic Cardiovascular Disease, Circulation, 107, 3109-3116.

U.S. Census Bureau. (2005). American Fact Finder. Web Site: http://factfinder.census.gov/servlet/SAFFFacts Retrieved January, 2005.

U.S. Centers for Disease Control and Prevention http://www.cdc.gov/chronicdisease/overview/index. Retrieved March, 2006.

Walsh, D., \& Radcliffe, J. (2002). Pain beliefs and perceived physical disability of patients with chronic low back pain, Pain, 97, 23-31.

Walsh, N. E. (2004). Global Initiatives in Rehabilitation Medicine, Archives of Physical Medicine and Rehabilitation, 85, (9), 1395-1402.

Warburton, D. E.R., Nicol, C. W., Bredin, S. S.D. (2006). Health Benefits of Physical Activity: the Evidence, CMAJ, 174, (6), 801.

Wolin, P., \& Tarbet, J. (1997). Rotator Cuff Injury: Addressing Overhead Overuse, The Physician and Sportsmedicine, 25, (6). www.physsportsmed.com.

Wong, J., \& Wong, S. (1999). Criteria for Determining Optimal Time of Discharge after Total Hip Replacement, Clinical Performance and Quality Health Care, 7, (4), 161-166.

www.afpafitness.com/articles/PostRehab, Retrieved 11/22/04 
Appendix A

Survey Phone List 


\section{CHIROPRACTORS}

ADIO Chiropractic Clinic

A Holistic Chiropractic Center

A Natural Balance Wellness Center

Accident \& Injury Center of the Five

Cities

Advanced Wellness Chiropractic Center

Arnesen Douglas DC

Baird William T. DC Inc.

Bend Chiropractic

Bernfeld Steven DC

Brigham Chiropractic

Community Health Centers

Cory Moore Chiropractic Inc

Davis Chiropractic Offices Inc

Family Chiropractic

Oak Park Wellness Clinic

Peterson Andrew DC

Phelan Kathryn

Pilloud Joseph DC

Pull Family Chiropractic

Quinn Chiropractic Center

Reed Sports Chiropractic

Rose Darci M DC

Ruda Chiropractic

Wolf Chiropractic

\section{PHYSICAL THERAPISTS}

A G Physical Therapy \& Sports Rehab

Bringle Physical Therapy

Cornerstone Physical Therapy

Giumini Cathy Physical Therapy

Hatcher Joanne MPT

Moscardi Physical Therapist

Performance Enhancement Therapy

Picacho PT

Physical Therapy Specialists

San Luis Sports Therapy

\section{PHYSICIANS \& SURGEONS, MD}

Ardito Joseph J MD

Arroyo Medical Group

Associated Surgeons of San Luis Obispo

Bella Vista Medical Group

Bernhardt David MD

Billon Sharon F MD

Central Coast Cardiothoracic \& Vascular Central Coast Gastroenterology Med

group

Clark Steve MD

Coastal Cardiology
489- 1326

481-2694

481-3442

481-7536

$773-4100$

489-3714

481-0754

474-4747

473-5989

773-4636

481-3652

473-9404

481-8807

481-8821

481-3499

773-1251

473-8895

473-0900

474-4224

481- 9696

481-1566

489-5661

481-8508

473-2200

481-5656

489-8447

473-0555

481-3442

473-7499

481-8272

773-9608

773-4395

473-7499

489-7912

474-9159

474-2600

546-0411

474-6110

474-8450

$481-5100$

541-6037

434-5530

473-8671

481-8233
418 E. Grand Ave. AG

Five Cities

260-A Station Way, AG

260 S Halcyon Rd. AG

567 Five Cities Drive Pismo

1400 W. Grand Ave. Grover

166 N 9th Grover Beach

172 Station Way

555 S. 13th St. Ste C. Grover

870 Price, PB

$336 \mathrm{~S}$ Halcyon AG

418 E. Grand Ave. A G

260 S. Halcyon Rd AG

138 W. Branch Ste. B AG

860 Oak Park BI. AG

1251 Shell Beach Rd. PB

575 S. 4th Grover Beach

881 Oak Park BI. Pismo Beach

415 El Camino RI AG

1551 W. Grand Av. Grover

192 N. 11th Grover Beach

121 N. Halcyon Rd. AG

$130 \mathrm{~S}$. Halcyon \#B AG

260 S. Halcyon Rd AG

117 S. Halcyon Rd AG

145 S. Halcyon Rd AG

1400 W. Grand Av. Grover

260-A Station Way AG

880 Oak Park BI. AG

901 Oak Park Blvd. PB

580 Cypress PB

855 4th Pismo Beach

880 Oak Park Bl. A G

1510 W. Branch St. AG

1184 E. Grand Av. AG

931 Oak Park BI. PB

921 Oak Park Blvd. PB

140 W Branch AG

877 Oak Park BI. PB

207 Bridge AG

310 James Way Ste.250 PB

921 Oak Park. Ste 101 PB

205 S Halcyon rd. AG

310 S Halcyon Rd. AG 
Coastal Medical Center

Coastal Village Primary Care

Cochran Janice MD

Devine Sean MD

Ferro Thomas D. MD

Fitchmun Cary MD

Fletcher Lorianna P. MD FACC

Foresman Gary E. MD

Fow Jonathan R. MD

Grisez James L MD

Guthrie Roger MD

Haar Johannes MD

Harris David L. MD

Hawthorne James N. MD

Hayashi Howard H MD

Hecht Harvey MD

Higginbotham Robert W. MD

Hori Gene MD

Janai Hillel K MD

Jones Ernest MD

Klosterman Paul MD

Lags Spine And Sports Care

Laird Michael T MD

Malotte Michael J MD

Med Plus Medical Center

Merrill Craig MD

Miller Stuart MD

Morgan Williams S MD

Mundorf Jeffrey B MD

Newman Lawrence MD

Palchak David MD

Pawlik Nancy MD FACS

Perrin Timothy J MD

Pismo Family Practice Inc

Pitrowski Anthony MD DMD

Puro David M MD FACC

Rahhal F Michael MD

Robertson Scott E MD

Safarik Randall MD PhD

Stallman Paul MD

Stallman Paul T MD

Stewart Robert G MD FACS

Thom Peter A MD

Thompson S Jefferey MD

Thoring Tod ND

Tidik Stephen J MD FACS

Ventana Health \& Medical Center Inc

Wallack Alice S MD

Weise Marc W MD

Whitehead Richard B MD
481-8268

$773-7440$

$773-1466$

473-2553

481-3685

474-2602

481-8233

481-3442

481-3685

489-1409

474-2602

474-8450

474-2604

473-7818

546-0411

773-4094

473-6640

773-0180

481-3166

474-2602

473-7818

473-3705

473-4949

481-1368

474-8450

473-6640

773-3160

473-3262

481-1007

474-8450

473-8983

783-7044

489-2448

773-0707

489-7600

481-8233

489-9600

489-2205

473-7950

481-3733

481-3776

481-1368

481-4202

473-2828

481-3499

544-8993

489-2205

474-2604

481-3685

473-3803
354 S Halcyon Arroyo Grande

855 4th PB

575 Price Pismo Beach

921 Oak Park Blvd. PB

860 Oak Park Blvd. Ste 10 AG

931 Oak Park BI. PB

310 Halcyon Rd AG

260 Station Wy AG

860 Oak Park Blvd. Ste 10

$345 \mathrm{~S}$ Halcyon BI

931 Oak Park BI. PB

877 Oak Park BI. PB

931 Oak Park BI. PB

921 Oak Park Blvd. PB

921 Oak Park Blvd. PB

855 4th PB

820 Oak Park Ste 204 AG

575 Price Pismo Beach

145 Bridge AG

931 Oak Park BI. PB

921 Oak Park Blvd. PB

310 S Halcyon Rd. AG

921 Oak Park Blvd. PB

268 S Halcyon Rd AG

877 Oak Park BI. PB

820 Oak Park Ste 204 AG

575 Price Pismo Beach

138 W Branch AG

921 Oak Park Blvd. PB

877 Oak Park BI. PB

1184 E Grand Av AG

310 S Halcyon Rd. Ste 101 AG

110 N Halcyon Rd AG

575 Price Ste 101Pismo Beach

310 S Halcyon Rd. AG

310 S Halcyon Rd. AG

310 S Halcyon Rd AG

901 Oak Park Blvd Suite 101 PB

921 Oak Park Blvd. PB

921 Oak Park Blvd.\#201-B PB

921 Oak Park Blvd. PB

268 S Halcyon Rd. AG

405 Traffic Way AG

260 Station Wy AG

860 Oak Park BI AG

921 Oak Park, PB

901 Oak Park Blvd Ste101 PB

931 Oak Park BI. PB

860 Oak Park Blvd Ste10 AG

354 S Halcyon Rd A G 
Appendix B

Informed Consent/Survey Script 


\section{Survey Script}

\section{$\underline{\text { Before asking Interview Questions }}$}

- Hello, my name is Starlene Marshall.

- I'm a Graduate student in the Kinesiology Department at Cal Poly carrying out the survey portion of my Master's project. The purpose of this survey is to gather responses regarding commonly treated medical conditions in the Arroyo Grande/5 Cities area, and ultimately I plan to develop a postrehabilitation conditioning program.

- May I take about 10 minutes of your time to ask you 5 questions to help complete the survey process?

- Your participation is voluntary. By continuing you are giving consent to participate, but you may decide to not answer specific questions.

- There are no anticipated risks involved in participating in this survey. Your responses will be kept confidential. Identity will not be associated with the data; a separate master list of names will be kept in a locked file and destroyed when no longer needed for the project.

- When answering the questions please be as specific as possible.

\section{$\underline{\text { After asking Interview Questions }}$}

- Thank you for answering my questions. If you would like to learn the results of this survey when it has been completed please give me your contact information at this time.

- If you have concerns about the way this survey was conducted you may contact Susan Opava, Dean of Research and Graduate Programs at 756-1508, sopava@calpoly.edu.

- Thanks again for your participation in this research! 
Appendix C

Survey 


\section{Survey Questions}

1. What are the 3-5 most common medical conditions treated in your facility?

1.

2.

3.

4.

5.

2. Of those conditions, which would you refer to a local health club offering a postrehab conditioning program?

1.

2.

3.

4.

5.

3. Have you ever referred patients to a post-rehab program at a fitness facility/health club?

4. What criteria and qualifications are you looking for in a personal trainer that would make you feel comfortable about referring a patient to him/her for post-rehab activities?

5. Do you have any concerns or reservations about referring to a trainer in a health club?

Health Professional ID \#:

Date: 
Appendix D

Program Outline 


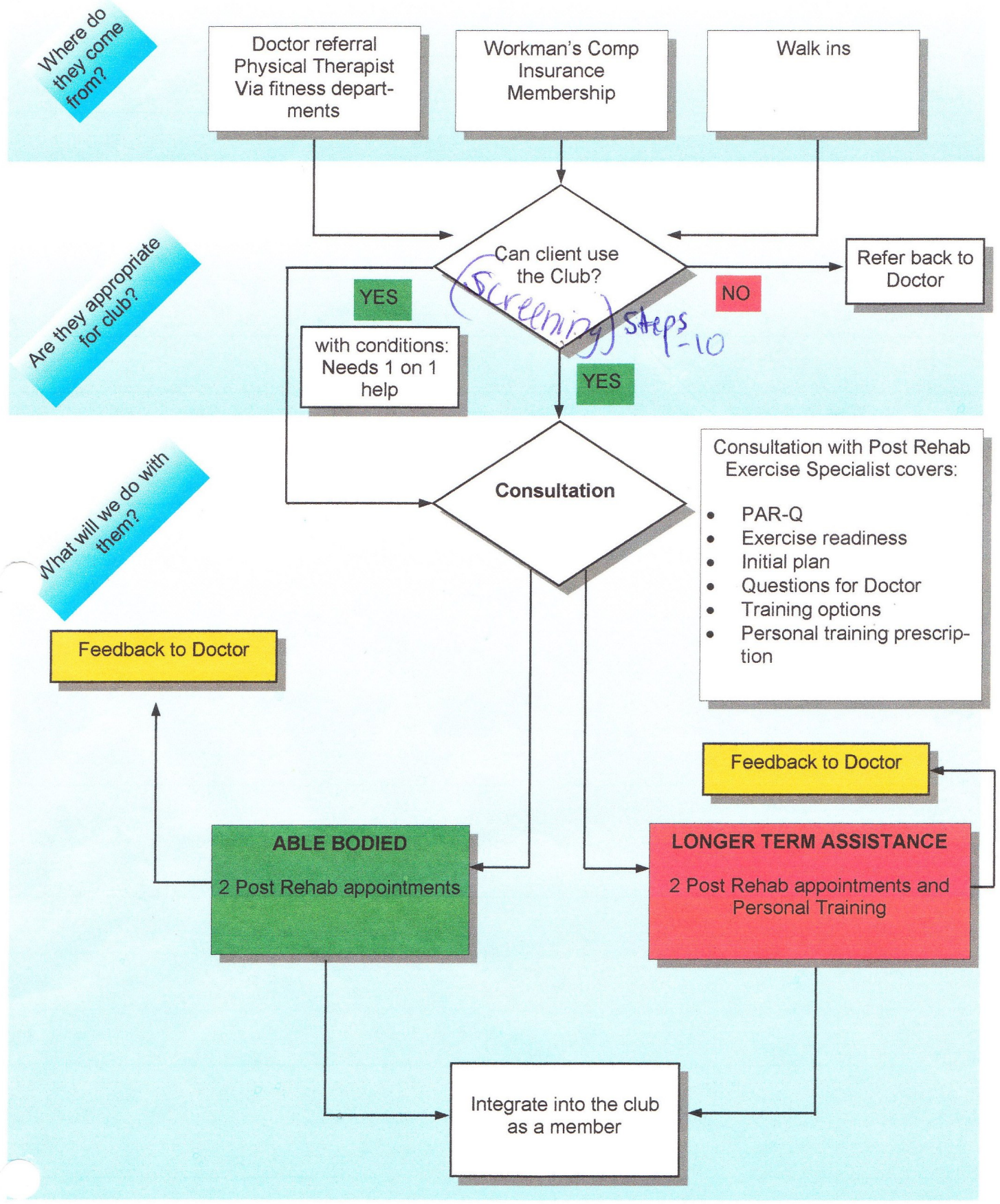




\section{Program Protocol}

\section{Program Design (Flowchart)}

A. Getting clients into the club: where do they come from?

○ Existing members- clients/friend

- Referral from medical authority

○ Walk-ins

B. Are they appropriate for the club?

Released from acute rehabilitation.

Medical clearance/referral

○ Yes: proceed to consultation/ Post-rehab appointments

○ No: refer back to doctor

C. Consultation with Post-Rehab Trainer

○ Exercise readiness (PAR-Q)

○ Healthy Living Lifestyle Assessment Questionnaire

○ Fitness Assessment/ Musculoskeletal Screening

○ Referral form

- Initial plan

○ Questions for Doctor

○ Training options

* The client will be sent back to the referring medical professional if he/she experiences any of the "Red Flags" as indicated by the AAHFRP. (Red Flags = Radiating pain, Numbness/tingling, Chest pain, Loss of function, Swelling, Open Wounds, Night pain).

D. Post-Rehab training appointments: 2 one-hour sessions to implement plan. Clients requiring more extensive one-on-one training may receive ongoing guidance from the trainer.

E. Feedback to doctor: 3 week progress report \& evaluation at end

F. 6 week or 3 month trial membership at reduced cost

G. Integrate as regular member 
- Post-Rehab clients obtain complete access to all club amenities; group exercises classes, steam/sauna, pool for lap swimming or Aqua aerobics, and executive locker room facilities.

II. Team in place

A. Personal Trainers (AAHFRP)

All Post-rehabilitation trainers will be certified through the American Academy of Health, Fitness and Rehabilitation Professionals for formality; receiving the Post-rehab Conditioning Specialist certification

- A two-day workshop and written test, a take home DVD series and case studies/essay portion. Prerequisites include: personal trainer certification and/or degree in a health-related discipline, or a state medical provider (e.g. MD, PT, DC).

B. Liaison/ Distribution Representative: distribution of marketing materials to the medical community, meets the office staff $\&$ builds rapport, the "face" of the club.

C. The Medical community: offices, clinics, and the staff (Administrative assistants)

\section{Networking}

A. Marketing Materials

- Brochures- quick read information describing the program and what the club has to offer.

- Referral pad- prepared referral pad for easy distribution

- Club passes

- Business cards

B. Clinics/Seminars: free educational lectures presented by club staff or a medical professional for members and guests.

- Weekly or monthly topics (nutrition/weight loss, proper exercise technique, low back care)

- Two time slots for accessibility i.e. noon and $6 \mathrm{pm}$ 
C. Social events: Open House, fundraisers etc.

Medical professionals to be included in these types of events to build the relationship and showcase the club. 


\section{Fitness Guidelines}

\section{Low Back}

Program Goals: Improve or maintain cardiovascular ability, improve core/abdominal strength, improve muscle strength, pain free range of motion.

Precautions:

○ Loss of sensation or radiating pain

- High impact activities

$\circ$ Excessive flexion or extension

\section{Sample Program}

Cardiovascular activities: walking, biking, water aerobics

30-60 minutes or in ten minute intervals, 5 days/wk, moderate intensity

Active ROM \& stretching exercises; hamstrings, back and piriformis muscles

Resistance exercises: machines, i.e. Nautilus, free weights, floor exercises 2-3 sets 10-15 repetitions.

Leg press

Leg curl

Rows

Chest press

Back extension

Ball wall squat

Spinal stabilization activities/core strength:

Plank

2 sets, $10-15$ reps

Hip bridges

Abdominal crunches

* Each program will be developed in conjunction with the medical authority based on each client's needs and goals.* 


\section{Fitness Guidelines}

Neck

Program Goals: Increase cervical muscle strength, and flexibility, increase shoulder and back strength, focus on posture and neutral spine.

Precautions:

○ Radiating pain, loss of sensation

○ headaches

- medical clearance

\section{Sample Program}

Cardiovascular conditioning: walking, stationary bike

30-60 minutes or in ten minute intervals 5 days/wk

Stretching of upper trapezius and shoulder muscles, cervical flexion/extension and lateral flexion, stretching of pectoral muscles.

Resistance exercises: machines, i.e. Nautilus, free weights, floor exercises

2-3 sets 10-15 repetitions.

Rows

Chest press

Lateral raises

Rotator cuff

Lat pull-down

Spinal stabilization

* Each program will be developed in conjunction with the medical authority based on each client's needs and goals.* 


\section{Fitness Guidelines \\ Shoulder}

Program Goals: Improve shoulder girdle strength/ rotator cuff strength, improve activities of daily living (ADLs), improve or maintain cardiovascular ability.

\section{Sample Program}

Cardiovascular conditioning: walking, stationary biking

30-60 minutes 5 days/wk moderate intensity

Active ROM \& stretching exercises; posterior shoulder girdle, triceps, pecs \& upper back

Resistance exercises: machines, i.e. Nautilus, free weights, floor exercises 2-3 sets 10-15 repetitions 2-3days/week.

Band/tubing exercises (internal/external rotation)

Wall push-ups

Rows

Lateral raises

Triceps extension

Chest press

Compound Row machine

* Each program will be developed in conjunction with the medical authority based on each client's needs and goals.* 


\section{Appendix E}

Program Description, Referral Sheet and Progress Report 


\section{KCF Post-Rehab Program}

\section{Goal}

To implement a course of action as recommended by the medical professional and to help move the client towards a healthy, active lifestyle.

Program: All Post-rehab program clients are on a one-time trial membership at reduced cost with the option to join the club at end of the program.

6 week or 3 month option as identified by medical professional

Prior to starting a client in the Post-rehab Conditioning Program the certified Post-rehab trainer needs to obtain:

Referral Form

Signed PAR-Q Form

Lifestyle Assessment Questionnaire

\section{Consultation}

Client Data, PAR-Q Medical Status, Lifestyle Assessment Questionnaire, Referral form, basic club Fitness Assessment with addition of Musculoskeletal Screening, and Conditioning Program plan

Fitness Assessment components: Heart Rate, Blood Pressure, Height/Weight, BMI, Flexibility, and Body Composition if requested. Once all paperwork is collected and the consultation is complete the trainer should be in contact with the Physician/Rehabilitation Professional to approve the initial exercise plan. Once the plan is approved the first appointment should be scheduled within one week to introduce the conditioning program.

\section{Conditioning Program}

2 initial one-hour appointments with a certified Post-rehab trainer to establish the exercise plan; a 3 week progress report and evaluation to follow

\section{Health Education}

Free health clinics presented by certified health, fitness and medical professionals for useful and accurate health information. (2 clinics per month, noon-time and evening, located in the Arroyo Grande club)

- Post-rehab program members obtain access to club amenities 
Sample Referral Sheet

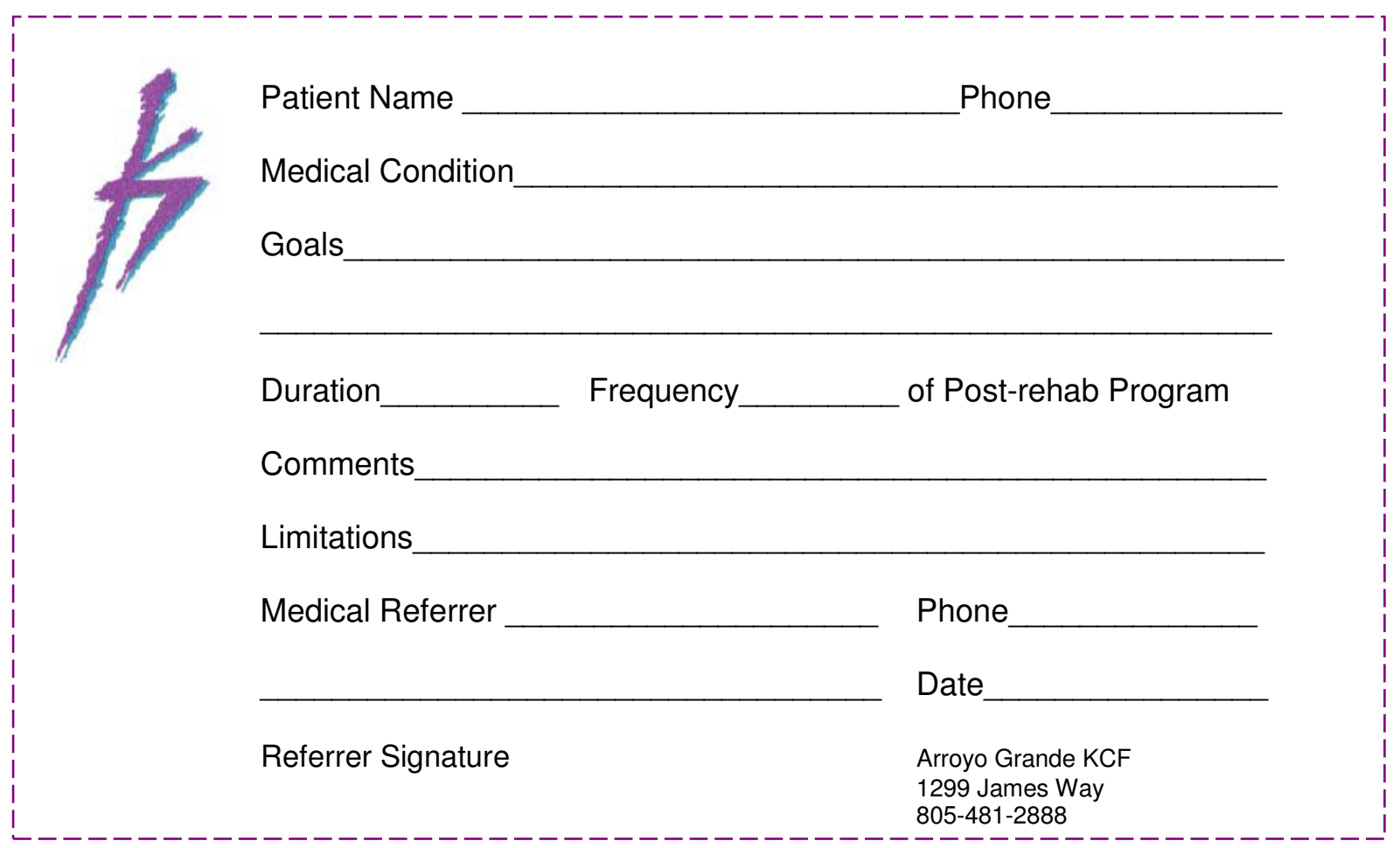




\section{POST-REHAB PROGRESS REPORT}

Client's Name:

Fitness Professional:

Program Start Date:

Medical Condition:

Session Date:

\section{CLIENT ASSESSMENT}

Flexibility

Strength

Cardiovascular

Balance

Function
Activity
Sets/Reps
Intensity
Limitations

Comments:

Signature Date: 
Appendix F

Consultation Forms 


\section{Client Data Questionnaire}

This information will help us to track your progress with our facility. Please answer each of these questions as accurately as you can. Should you have any questions, feel free to ask. Your responses will be treated in a confidential manner.

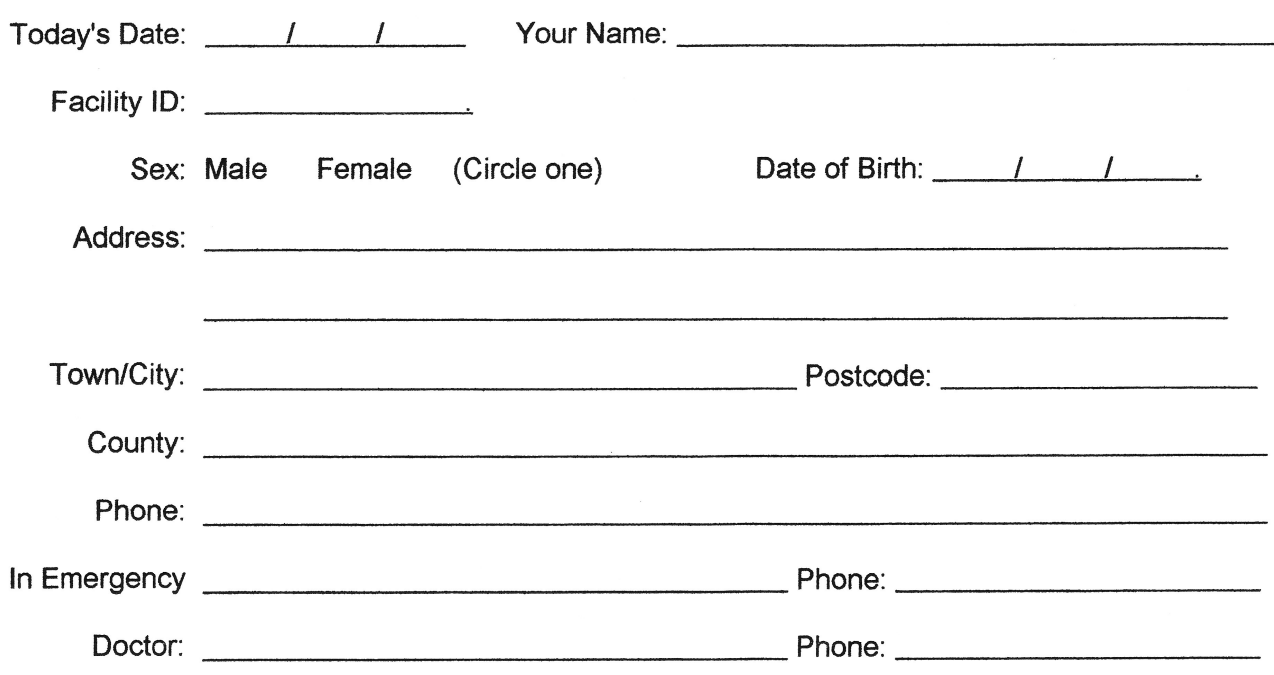




\section{PAR-Q Medical Status}

Being more active is very safe for most people. However, some people should check with their doctor before they start becoming much more active. If you are planning to become much more physically active, start by answering the seven questions in the box below. If you are between the ages of 15 and 69 , the PAR-Q will tell you if you should check with your doctor before you start. If you are over 69 years of age, and you are not used to being very active, check with your doctor.

Common sense is your best guide when you answer these questions. Please read the questions carefully and answer each one honestly: place a tick in the space to the left of the question to answer "Yes." Leave blank if your answer is "No." Please ask if you have any questions. Your responses will be treated in a confidential manner.

[ ] Has your doctor ever said that you have a heart condition and that you should only do physical activity recommended by a doctor?

[ ] Do you feel pain in your chest when you do physical activity?

[ ] In the past month, have you had chest pain when you were not doing physical activity?

[ ] Do you lose your balance because of dizziness or do you ever lose consciousness?

[ ] Do you have a bone or joint problem that could be made worse by a change in your physical activity?

[ ] Is your doctor currently prescribing drugs (for example, water pills) for your blood pressure or heart condition?

[ ] Do you know of any other reason why you should not do physical activity?

If you answered YES to one or more questions, talk with your doctor by phone or in person BEFORE you start becoming much more physically active or BEFORE you have a fitness appraisal. Tell your doctor about the PAR-Q and which questions you answered YES. You may be able to do any activity you want - as long as you start slowly and build up gradually. Or, you may need to restrict your activities to those that are safe for you. Talk with your doctor about the kinds of activities you wish to participate in and follow his/her advice.

If you answered NO honestly to all questions, you can be reasonably sure that you can:

- Start becoming much more physically active - begin slowly and build up gradually. This is the safest and easiest way to go.

- Take part in a fitness appraisal - this is an excellent way to determine your basic fitness so that you can plan the best way for you to live actively.

Even if you answered no to all questions, you should delay becoming much more active:

- If you are not feeling well because of a temporary illness such as a cold or a fever - wait until you feel better.

- If you are or may be pregnant - talk to your doctor before you start becoming more active.

Please note: If your health changes so that you then answer YES to any of the above questions, tell your fitness or health professional. Ask whether you should change your physical activity plan.

Informed Use of the PAR-Q: The Canadian Society for Exercise Physiology, Health Canada, and their agents assume no liability for persons who undertake physical activity. If in doubt after completing this questionnaire, consult your doctor prior to physical activity.

I have read, understood and completed this questionnaire. Any questions I had were answered to my full satisfaction. Name:

Signature:

Signature of Parent

or Guardian (for participants under the age of majority)
Today's Date:

Witness:

\begin{tabular}{|l|l|}
\hline PAR-Q Medical Status & Page 1 \\
\hline & \\
\hline
\end{tabular}




\section{Healthy Living Lifestyle Assessment Questionnaire}

This form asks you a variety of questions about your lifestyle habits, and takes about 3 minutes to complete. Please fill in the information requested, or place a check in the appropriate space. We thank you for your time and effort in completing this questionnaire.

\section{Personal Information}

Today's Date: $\frac{1}{1}$ Your Name: $\_$Height: $\_$Sex: $\square$ Male $\square$ Female
Weight: $\_$pounds
What is the most you have ever weighed?
Are you NOW trying to:
$\square$ Lose weight
$\square$ Stay about the same $\quad \square$ Not trying to do anything

\section{Medical History}

Yes No

Has your father or brother had a heart attack or died suddenly of heart disease before age 55 years; has your mother or sister experienced these heart problems before age 65 years?

Has a doctor told you that you have high blood pressure (more than $140 / 90 \mathrm{~mm} \mathrm{Hg}$ ), or are you on medication to control your blood pressure?

OR

If you know your blood pressure, please check the appropriate category:

$\begin{array}{ll}\square \text { Less than } 120 / 80 \mathrm{~mm} \mathrm{Hg} & \square \text { 140/90 to } 159 / 99 \\ \square 120 / 80 \text { to } 129 / 84 & \square \text { 160/100 to } 180 / 110 \\ \square \text { 130/85 to } 139 / 89 & \square \text { More than } 180 / 110\end{array}$

Is your total blood cholesterol greater than $240 \mathrm{mg} / \mathrm{dl}$, or has a doctor told you that your cholesterol is at a high risk level? OR

If you know your blood cholesterol, please check the appropriate category:
$\square$ Less than $160 \mathrm{mg} / \mathrm{dl}$
200-219
$\square$ More than 260
$\square$ 160-179
$\square$ 220-239
$\square$ Do not know
$\square$ 180-199
口 240-260

Do you have diabetes?

During the past year, would you say that you experienced enough stress, strain, and pressure to have a significant effect on your health? 


\section{Health and Nutrition}

In general, compared to other persons your age, rate how healthy you are:

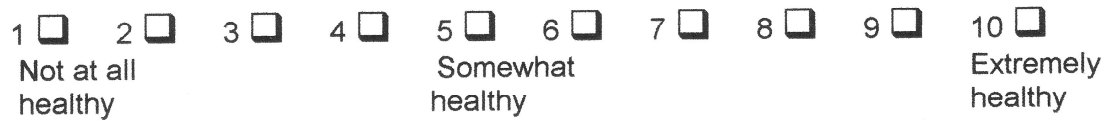

Outside of your normal work or daily responsibilities, how often do you engage in exercise that at least moderately increases your breathing and heart rate, and makes you sweat, for at least 20 minutes (such as brisk walking, cycling, swimming, jogging, aerobic dance, stair climbing, rowing, basketball, racquetball, vigorous yard work, etc.).

$\square$ or more times per week

3 to 4 times per week

1 to 2 times per week

$\square$ Less than 1 time per week

$\square$ Seldom or never

Do you eat foods nearly every day that are high in fat and cholesterol such as fatty meats, cheese, fried foods, butter, whole milk, ice cream, or eggs?

$\square$ Yes $\square$ No

On average, how many servings of fruit and vegetables do you eat per day? (One serving = 1 medium fruit, $1 / 2$ cup of chopped, cooked, or canned fruit/vegetable, 3/4 cup of fruit or vegetable juice).
$\square$ none
1-2
$3-4$
5-6
7-8
9 or more

On average, how many servings of bread, cereal, rice, or pasta do you eat per day? (One serving $=1$ slice of bread, 1 ounce of ready-to-eat cereal, $1 / 2$ cup of cooked cereal, rice, or pasta).
$\square$ none
$\square 1-2$
- 3-5
$\square 6-8$
9-11
$\square 12$ or more

\section{Lifestyle Habits}

How have you been feeling in general during the past month?

$\begin{array}{lll}\square \text { In excellent spirits } & \square \text { In good spirits mostly } \\ \square \text { In very good spirits } & \square \text { I've been up \& down in spirits a lot } \square \text { In very low spirits }\end{array}$

On average, how many hours of sleep do you get in a 24-hour period?
$\square$ Less than 5
$\square$ to 6.9
$\square 7$ to 9
More than 9

How would you describe your cigarette smoking habits?

Never smoked

$\square$ Used to smoke

How many years has it been since you smoked?

$\begin{array}{ll}\square \text { less than } 1 \text { year } & \square-15 \\ \square \text { More than } 15\end{array}$


$\square$ Still smoke

How many cigarettes a day do you smoke on average?

\begin{tabular}{|c|c|c|}
\hline$\square$ 1-10 & $\square$ 21-30 & $\square$ More than 40 \\
\hline$\square$ 11-20 & $\square 31-40$ & \\
\hline
\end{tabular}

How many alcoholic drinks do you consume? (A "drink" is a glass of wine, a wine cooler, a bottle/can of beer, a shot glass of liquor, or a mixed drink).

$\square$ Never use alcohol $\square$ Less than 1 per week $\square 1$ to 6 per week

$\square 1$ per day $\square 2$ to 3 per day $\square$ More than 3 per day

When driving or riding in a car, do you wear a seat belt:

$\square$ All or most of the time $\square$ Some of the time $\square$ Once in awhile $\square$ Rarely or never 


\section{Musculoskeletal Screening}

- Recognize potential musculoskeletal concerns that could become problematic during exercise.

1. [ ] Postural Screen- quick observation, identify gross asymmetries Comment:

2. [ ] Active Shoulder ROM- both arms overhead, elbows extended, touch dorsal surface of hands together

- Note any pain- radiating pain= red flag Comment:

3. [ ] Anterior Shoulder Flexibility- interlocks fingers, hands behind head

- Limited flexibility- stretch pecs and strengthen posterior shoulder

Comment:

4. [ ] Cervical ROM- looks straight then turn head 45 degree angle chin to chest

Comment:

- Radiating pain/numbness= refer to physician

5. [ ] Resisted Internal/External Rotation at shoulder- rotator cuff integrity

Comment:

- Check for weakness and pain

6. [ ] Full Knee Extension- seated active knee ROM

- Should be able to fully extend the knee

- Check for pain in knees or low back

Comment:

7. [ ] Resisted Knee Flexion and Extension- from seated position starting at 90 degree angle have client straighten leg to 45 degree angle, apply resistance and hold. Client moves leg to 90 degrees and hold against resistance in flexion

- Bilateral comparison- integrity of knee 
Comment:

8. [ ] Single Knee to Chest- Questions: Do you have acute low back pain? History of lumbar disk herniation or surgery? Lay supine bring knee to chest, repeat with other leg

- Check for discomfort and stiffness

- Identify lack in flexibility and/or low back pain

Comment:

9. [ ] Hamstring Flexibility- have client lay supine lift leg with knee fully extended

- Check for movement in hip

- Discontinue if pain

- Bilateral comparison

Comment:

10. [ ] Balance- tip toe and heel walk, and single leg stance

- MS, Vertigo, CVA = balance altered

- If a problem is identified refer client to licensed MD for evaluation

Comment: 
Appendix G

Lecture/Clinic Information 


\section{Kennedy Club Fitness}

\section{Low Back Care Clinic}

\section{Presented by a}

local Physical Therapist Monday 12:00 noon Arroyo Grande location

Topics include: LB pain, Stretching, and the Importance of Abdominal Strength

You don't want to miss this informational

\section{FREE clinic}

\section{Guests Welcome}

Questions please call 481-2888 or ask the Fitness Director 


\section{Low Back Clinic Notes}

The Low Back Care clinic was held in the Arroyo Grande KCF and started at approximately 12:00pm.

The presenter opened the clinic by introducing herself and asking the members questions regarding back pain. This took approximately 10 minutes. Some questions asked were, "How many of you have ever had back pain?" "How often do you experience back pain?" "What are some treatment methods; medication, stretching, massage?" "Have you ever been through Physical Therapy?"

During the next 20 minutes, acute and chronic low back pain were discussed along with treatment options such as physical therapy modalities: heat therapy, ultrasound, massage, and exercise. This led into flexibility. A segment was devoted to demonstrations of stretching exercises to reduce stress on the joints and alleviate back pain. The stretches included: Cat stretch on all fours, figure 4/Piriformis stretch, seated hamstring/gluteal stretch, supine single-leg hamstring stretch, and supine cross over stretch.

The next topic covered was the importance of Abdominal/Core strength, lasting about 15 minutes. Spinal stabilization was discussed including the concept of "neutral spine". She talked about "Core" strength, the transversus abdominus, and keeping the trunk/midsection strong. Some abdominal/core activities were introduced and demonstrated.

The last part of the clinic was open to questions. The presenter was able to interact with the members and club staff. 
KENNEDY CLUB FITNESS
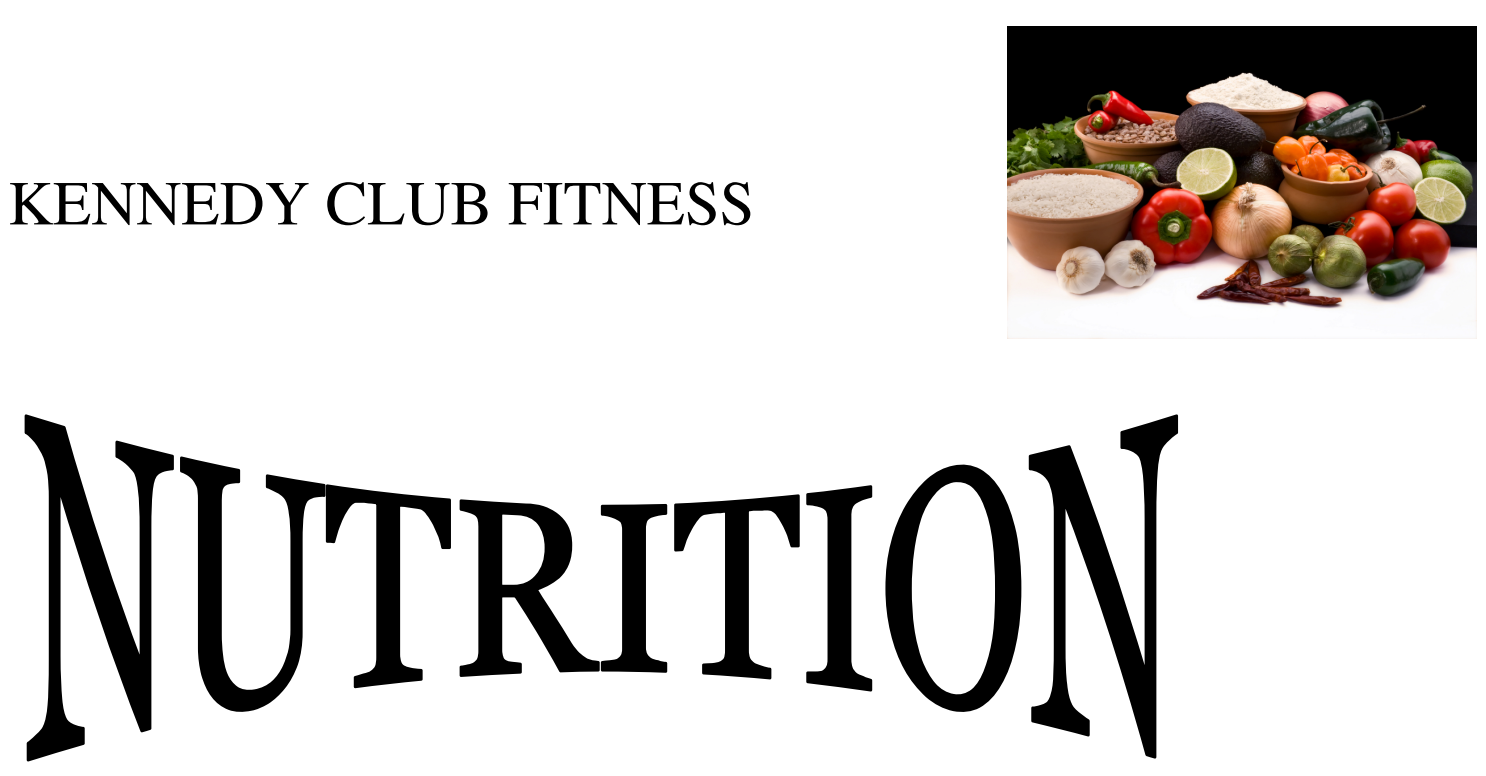

Seminar

Presented by Ginger Lordus

Personal Trainer and certified Nutritionist

Healthy Eating Habits

\section{Thursday 12:00 noon \\ Arroyo Grande location}

FREE clinic

Guests Welcome 


\section{Nutrition Seminar Notes}

The Nutrition seminar was given by a Kennedy Club Fitness personal trainer and certified nutritionist Ginger Lordus, around noon in the Arroyo Grande club. Light refreshments were provided such as grapes, halves of bananas, multi-grain crackers and cheese. About 5 minutes was used for introduction.

The first half of the seminar encompassed healthy eating habits, discussing the idea of "eating smaller, more frequent meals", "snacking on fruits and vegetables to get the recommended number of servings", and "eating less processed/packaged foods". Statements were made such as; "healthy eating is not about dieting but rather eating a variety of foods", and "healthy eating can boost energy and stabilize mood and blood sugar". Ideas for healthy snack options were suggested which included nuts and cheese, apples with peanut butter, berries, and fresh vegetables like carrots and broccoli. The talk lasted about 30 minutes.

Portion size was the next topic discussed, lasting approximately 15 minutes. Actual food items were displayed; specifically one slice of wheat bread, $1 / 2$ cup of rice, one small-medium sized apple and one cup of yogurt were set out on the table as visual aids. Proper serving sizes for the healthy snack items (nuts, berries and vegetables) were shown by using her hand/fist.

Closing the seminar, the presenter reminded the members to choose a variety of foods, and to make a "more colorful plate". Other statements like "Don't pick a fad diet" and take small steps, making changes little by little until it becomes a habit. The seminar lasted about 50 minutes. Time was left for questions and discussion. 
Appendix $\mathrm{H}$

Brochure 

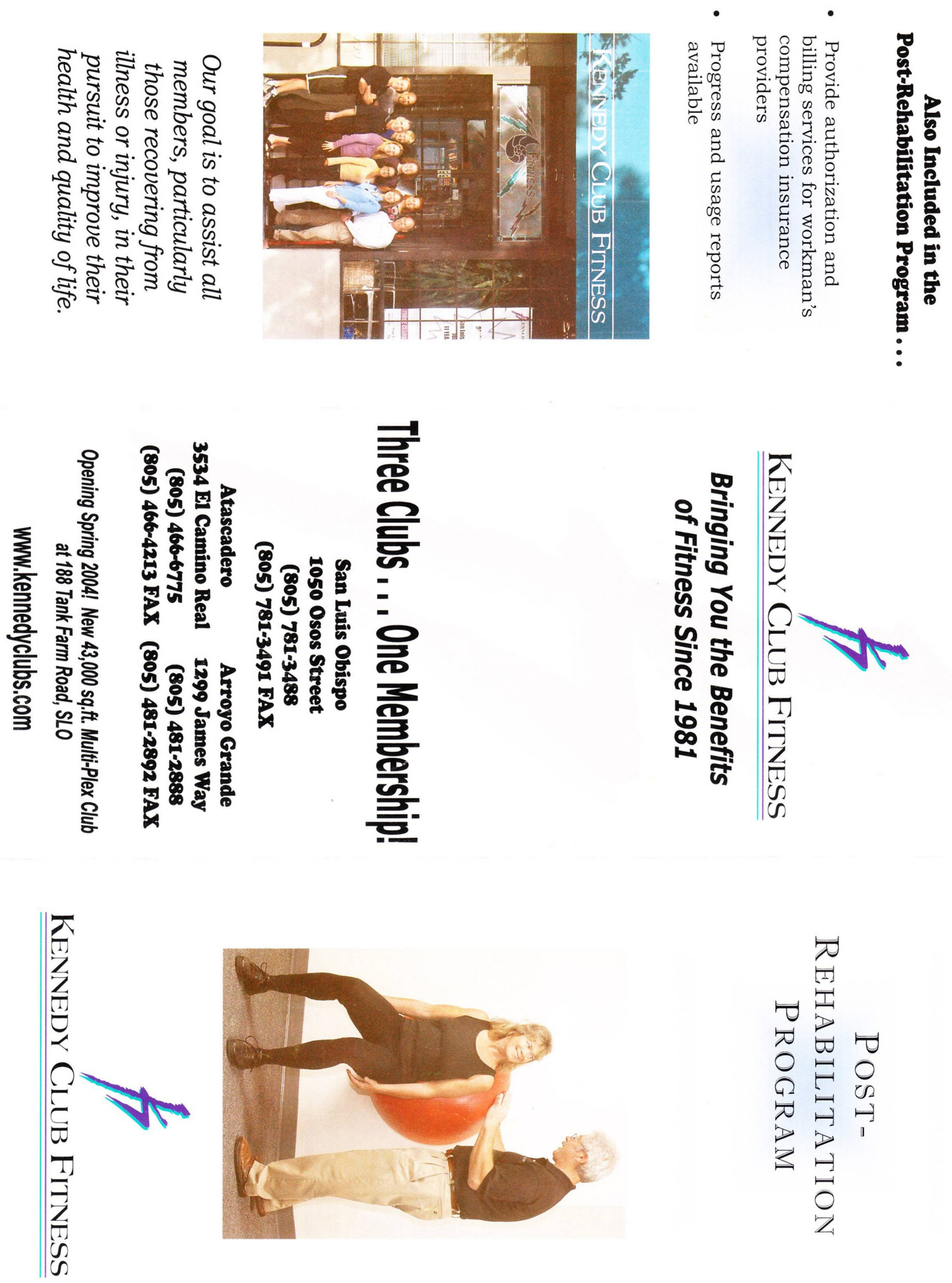

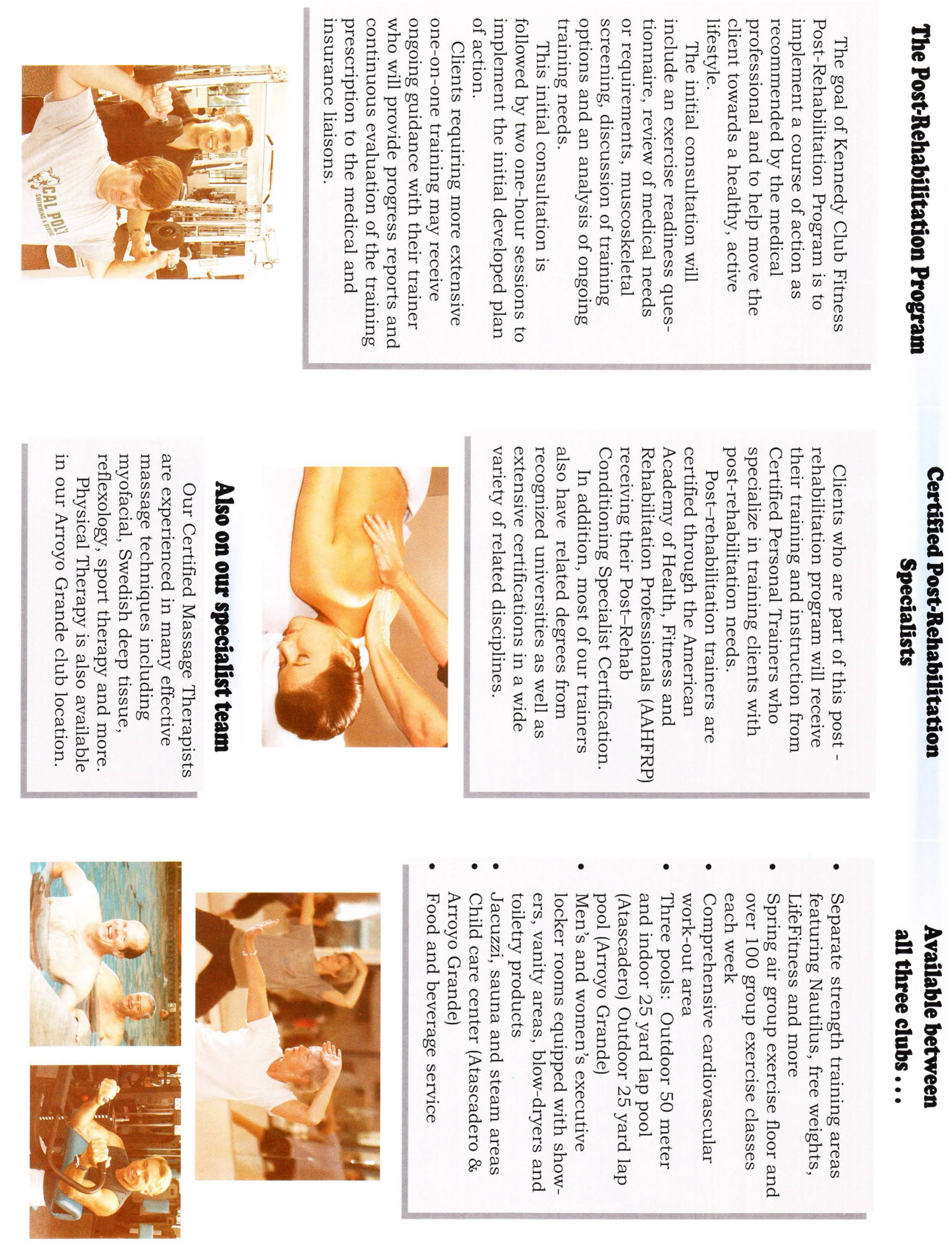